\author{
RESEARCH ARTICLE \\ 10.1029/2018JF004853 \\ Key Points: \\ - Wet/dry reach lengths along the San \\ Pedro River approximately follow a \\ power law frequency size \\ distribution \\ - Power law distributed wet/dry \\ reaches result from self-affine fractal \\ variations of the depth to bedrock \\ and the channel longitudinal profile \\ - Tight coupling between hydrologic \\ and geomorphic processes of \\ dryland alluvial rivers results in \\ complex spatiotemporal behavior
}

Supporting Information:

- Supporting Information S1

- Data Set S1

Correspondence to:

Z. C. Williams,

williamsz@uncw.edu

Citation:

Williams, Z. C., Pelletier, J. D., \& Meixner, T. (2019). Self-affine fractal spatial and temporal variability of the San Pedro River, southern Arizona. Journal of Geophysical Research: Earth Surface, 124, 1540-1558. https://doi. org/10.1029/2018JF004853

Received 20 AUG 2018 Accepted 24 APR 2019 Accepted article online 12 MAY 2019 Published online 25 JUN 2019

(C)2019. American Geophysical Union. All Rights Reserved.

\section{Self-Affine Fractal Spatial and Temporal Variability of the San Pedro River, Southern Arizona}

\author{
Z. C. Williams ${ }^{1}$ (D) J. D. Pelletier ${ }^{2}$ D , and T. Meixner ${ }^{2}$ \\ ${ }^{1}$ Department of Physics and Physical Oceanography, University of North Carolina Wilmington, Wilmington, NC, USA, \\ ${ }^{2}$ Department of Geosciences, University of Arizona, Tucson, AZ, USA
}

Abstract Prevailing mathematical models of alluvial channel evolution generate smooth, idealized longitudinal profiles. Alluvial channel longitudinal profiles in nature, however, have substantial multiscale spatial and temporal variability. In this paper we quantify the spatial and temporal hydrologic and geomorphic variability of a 90-km-long reach of the San Pedro River (San Pedro River) in southeastern Arizona and compare that variability to numerical models designed specifically to honor the spatial and temporal variability of alluvial channel systems in nature. A key motivation of this work is the power law frequency size distribution of wet and dry reaches observed in the San Pedro River. We demonstrate that such a distribution is consistent with self-affine fractal variations of the depth to bedrock and the channel longitudinal profile. At large spatial scales, spatial variations in depth to bedrock control the accommodation space for groundwater, which, in turn, controls spatial variations in surface water discharge. At small spatial scales, the longitudinal profile controls spatial variations in surface water discharge by changing the distance between the channel bed and the water table. These results underscore the complex spatiotemporal behavior of dryland alluvial rivers and the tight coupling that is possible between hydrologic and geomorphic processes in such systems.

\section{Introduction}

\subsection{Introduction}

River and stream flow conditions vary over a continuum of states from ephemeral (persistently dry) to perennial (persistently wet). The flow regime results from a complicated combination of interactions among the hydroclimatic regime, the alluvial channel, and the underlying groundwater system (Jaeger et al., 2017). Intermittent rivers are those in which flow ceases for some period of time at one or multiple points along the river network. Ephemeral and intermittent reaches occur where channel transmission losses recharge the underlying groundwater system; these are often referred to as losing reaches (Woessner, 2000). Perennial reaches are fed by discharge from the underlying groundwater system and are referred to as gaining reaches. Gaining and losing conditions may occur serially such that perennial reaches are interrupted by ephemeral and intermittent reaches (Rushton, 2007). Intermittent and ephemeral rivers are typically associated with dryland river systems because of the highly episodic nature of streamflow-generating events and the spatially variable groundwater fields supplying baseflow to perennial reaches. However, conservative estimates suggest that nearly half of the total length of the world's channel networks are intermittent or ephemeral (Datry et al., 2014). Shifting climate regimes and increasing anthropogenic pressure could significantly increase the already global extent of intermittent and ephemeral conditions (Palmer et al., 2008). Recent analyses of four active drainage networks in several mountainous headwater basins in California show that stream networks expand and contract seasonally with varying degrees of hydrologic connectivity (Godsey \& Kirchner, 2014). While climatic and geologic conditions varied across the study sites, drainage network properties such as flowing stream length and number of connected flowing sources were all found to be power law functions of discharge, suggesting that intermittency is a generic feature of river systems. Despite the global existence of intermittency, the longitudinal structure and physical controls that give rise to spatially and temporally variable flow conditions are not yet well constrained, possibly because intermittency is observed across all hydroclimatic regimes and geomorphological zones (Jaeger et al., 2017). We chose the San Pedro River, located in southeastern Arizona, USA, as the focus of study because it is one of the last remaining free-flowing perennial streams in the southwestern United States. While the San Pedro River is considered a perennial stream, perennial flow is not spatially continuous along the entire extent of the river. Instead, perennial reaches are interrupted serially by both intermittent and ephemeral reaches. As 
such, the San Pedro River has been extensively investigated for understanding of how to preserve the perennial nature of the river and the over 400 species that depend on it. In this paper we show that multiscale variability in both depth to bedrock (DTB) and depth to water table (DWT) profiles along the San Pedro River control the spatial distribution of wet/dry reaches.

Topography-groundwater interactions are well understood in the context of unconfined hillslope aquifers (e.g., O'Loughlin, 1981; Tóth, 1963) and in fluvial systems where groundwater flows perpendicular to streamflow (e.g., groundwater flow cross sections). Much less is understood about the longitudinal variations of groundwater along-stream channels or the controls on the surface flow state (e.g., gaining versus losing) in arid landscapes. For hillslopes and flows between parallel streams, dimensional analysis suggests high recharge rates and low hydraulic conductivity result in water tables that are diffuse replicas of topography (Haitjema \& Mitchell-Bruker, 2005). In mountainous terrain, steep topography results in steep hydraulic gradients leading to a groundwater table that also may follow topography (Tóth, 1963). On the other hand, recharge-controlled water tables typically occur in regions of low relief or where the ratio of recharge to hydraulic conductivity is low (e.g., arid mountainous regions and arid valleys). In this case, while gaining and losing stream conditions may be quantified at some position along the stream channel, the longitudinal structure of gaining and losing reaches are not described as the analysis pertains to one-dimensional flow cross sections.

Many conceptual and mathematical models of alluvial channel longitudinal profiles lack the multiscale variability observed in natural rivers. For example, conservation of mass combined with a slopeproportional, transport-limited model of sediment flux implies a diffusion model for alluvial channel profiles (e.g., Paola, 1992). This model has been successfully applied to quantifying the alluvial channel response to base-level changes (e.g., Begin, 1988). Many natural channel profiles, however, evolve in response to a large number of small perturbations in both tectonic activity (which generates relief within channels) and weather/climate (which controls sediment flux along channels) over a wide range of spatial and temporal scales. This observation suggests that a model that combines the diffusive-like behavior of alluvial channel longitudinal profiles with a stochastic forcing term(s) to represent the effects of tectonics and/or weather/climate could be useful in reproducing the multiscale variability of longitudinal profiles in nature. Many fluvial channel evolution models have employed stochastic forcing (e.g., Dibiase \& Whipple, 2011; Lague et al., 2005; Tucker, 2004; Tucker \& Bras, 2000), but in most cases stochasticity has been used to scale deterministic model parameters in order to capture the effects of runoff variability on long-term erosion rates rather than to generate profile morphologies with multiscale variability. In this paper we present a model for alluvial channel profile evolution by stochastic variations in sediment flux and compare the model output to data for the San Pedro River (San Pedro River) of southern Arizona (Figure 1). All data analyzed are well described by power functions that imply self-affine fractal behavior in space and time of the underlying processes. Two models are then put forth incorporating only rudimentary aspects of fluvial dynamics, and are also well described by power functions. Our data analysis is specific to the San Pedro River, but the concepts and model may be applicable to other semiarid fluvial systems as the concepts and processes we discuss occur in dryland alluvial systems generally.

\subsection{Study Region and Motivating Observations}

To motivate the study it is helpful to first examine the longitudinal profile of the San Pedro River (Figure 2). Figure 2a plots the San Pedro River longitudinal profile from the Mexico-United States border to just beyond Benson, Arizona. This profile is the elevation of a steepest-descent pathway extracted from a hydrologically corrected $1 \mathrm{~m}$ /pixel Digital Elevation Model (DEM) constructed from the ground returns of an airborne lidar data set acquired in June 2004 (Farid et al., 2006). To first order, the profile is linear with a slope of 0.0022 $\mathrm{m} / \mathrm{m}$. Superimposed on the linear profile is a large-wavelength $(\sim 100 \mathrm{~km})$ zone of slopes that decrease and then increase with distance downslope, as well as smaller-scale $(\sim 0.1-10 \mathrm{~km})$ variations in elevation with amplitudes of up to several meters (Figure $2 b$ ). The power spectrum, $P$, of the detrended longitudinal profile plotted in Figure $2 \mathrm{~b}$ is best described as a power law function of wave number, $v$, with an exponent of $\sim-1.8$ (Figure 2c):

$$
P(v) \propto v^{-\beta}
$$

This power law relationship is observed over the approximate wave number of range of $\sim 10^{-1.65} \mathrm{~km}^{-1}$ to $10^{1.5} \mathrm{~km}^{-1}$, which are commensurate with the dominant scale of range-bounding faults (Fletcher \& 


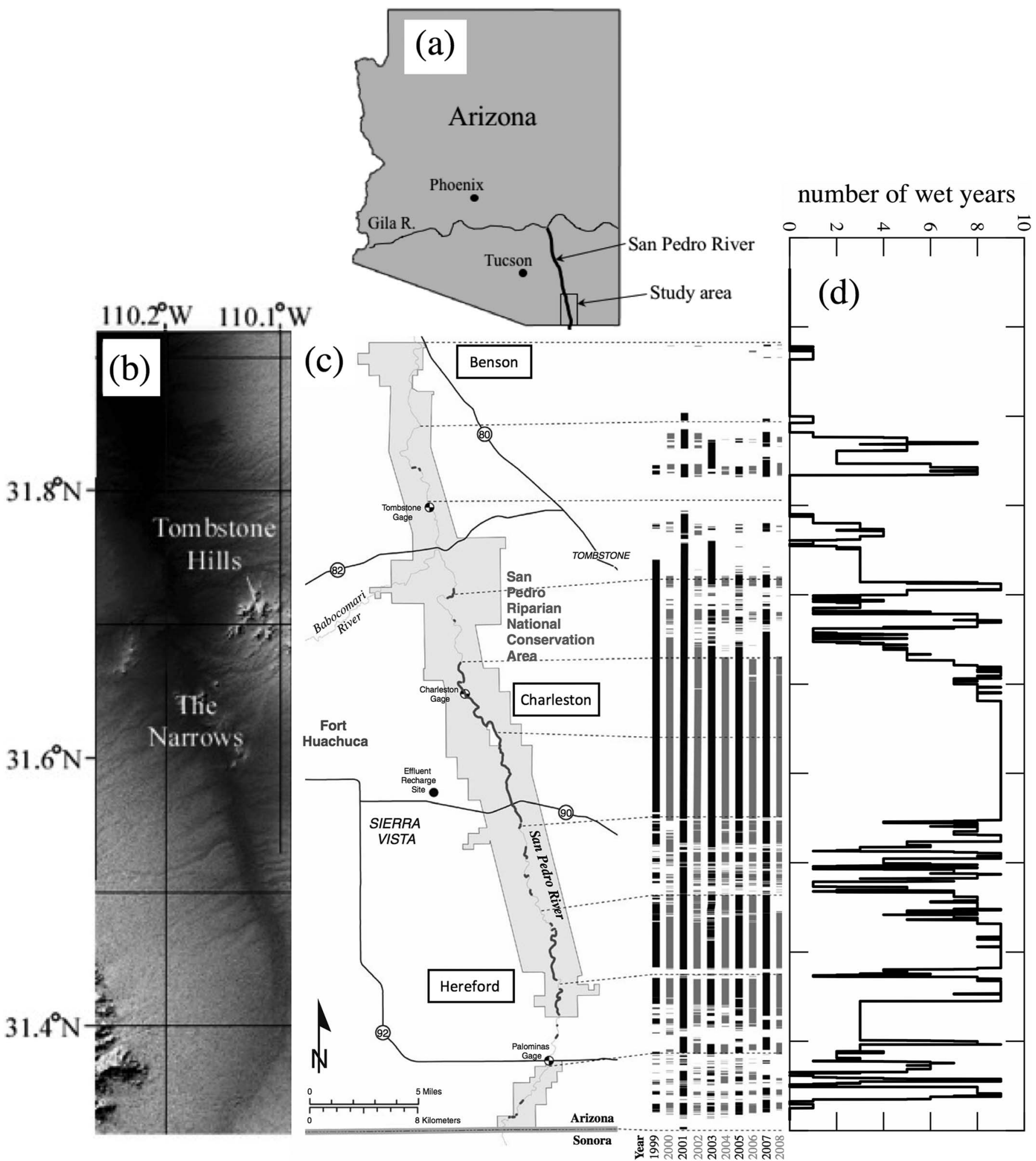

Figure 1. Maps of the study region and data for the occurrence of wet/dry reaches surveyed from 1999 to 2008. (a) Map of the state of Arizona showing the location of the San Pedro River (San Pedro River). (b) Shaded relief map and (c) map of the course of the San Pedro River taken from Turner and Richter (2011). In (c) the wet reaches observed from 1999 to 2008 are shown in black and gray. Panel (d) shows the number of wet years as a function of distance along the channel profile. 

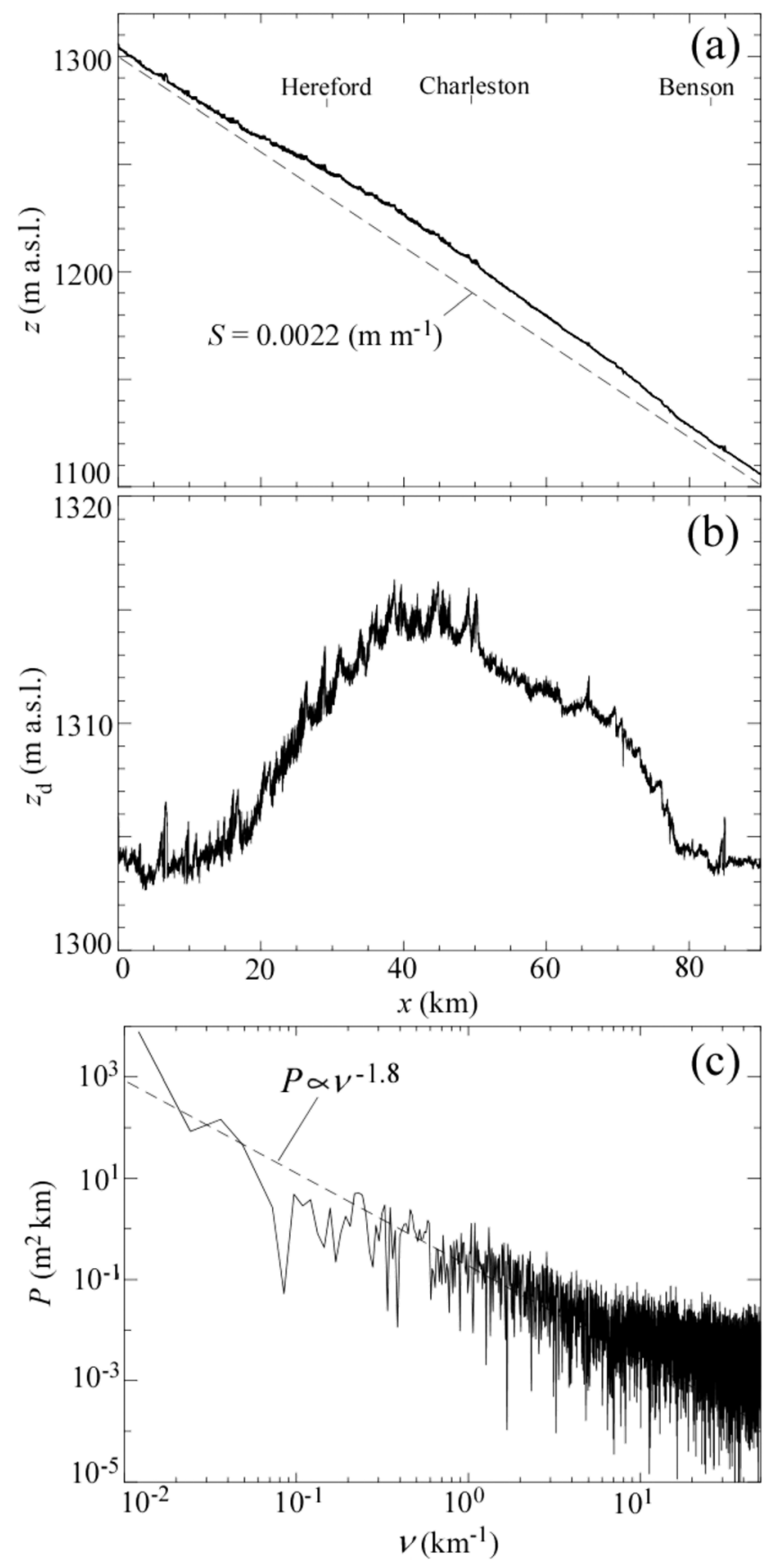

Figure 2. The longitudinal channel morphology of the San Pedro River surface is characterized by (a) the longitudinal elevation profile $(z(x))$, (b) the longitudinal profile with mean slope $(0.0022 \mathrm{~m} / \mathrm{m})$ removed $\left(z_{\mathrm{d}}(x)\right)$, and (c) the power spectrum $(P(v))$ of $z_{\mathrm{d}}$ as a function of wave number $(v)$. The power spectrum approximately follows a power law function of wave number with an exponent of $\sim-1.8$.
Hallet, 1983) and to the hillslope scale, respectively (Perron et al., 2008). Functions that have power law power spectra as a function of wave number (i.e., equation (1)) or frequency, $f$ (if the series is a time series) are said to exhibit self-affine fractal behavior. A signal (or a time series) $f(x)$, is a self-affine fractal if rescaling both the independent and dependent variable by the constants $b$ and $b^{H a}$ respectively, yields a statistically equivalent signal. This rescaling is $f(x) \rightarrow b^{H a} f(b x)$, where $H a$ is the Hausdorf dimension. The Hausdorf dimension is theoretically related to the spectral exponent through the relation $\beta=2 H a+1$. A signal characterized by a power law power spectra exponent $\beta$ is a self-affine fractal across all length scales for which equation (1) holds. Series with $\beta \leq 1$ that have a Gaussian distribution of values are referred to as fractional Gaussian noises (fGn), while series with $\beta>1$ that have a Gaussian distribution of the increments between adjacent values are referred to as fractional Brownian motions (fBm). For further reference on self-affine fractals, see Malamud and Turcotte (1999). As the value of $\beta$ increases in a fGn or $\mathrm{fBm}$, the series becomes more autocorrelated. Almost all spatial or time series in nature have some autocorrelation, but self-affine fractal series are distinguished by the fact that they have autocorrelation over a wide range of scales with the strength of the autocorrelation decaying slowly, that is, as a power law function of the distance or time separating points in the series, rather than as an exponential or other rapidly decaying function.

Self-affine fractal behavior in space and/or time has been observed in a wide range of geologic phenomena, including fluvial topography (Huang \& Turcotte, 1989), porosity/permeability in sedimentary basins (Neuman, 1990), atmospheric temperatures (Pelletier, 1998), humidity (Cho et al., 2000), precipitation (Venugopal et al., 1999), river discharges (Pelletier \& Turcotte, 1997), and soil moisture (Pelletier et al., 1997). In all of these examples there are natural upper and lower limits to self-affine fractal behavior; for example, in the fluvial topography case self-affine fractal behavior breaks down at the hillslope scale (Perron et al., 2008). Mathematical models have been proposed to help explain self-affine behavior in some geologic phenomena (e.g., Pelletier \& Turcotte, 1997; Sornette \& Zhang, 1993), but in many instances the reason for self-affine fractal behavior remains unclear.

The San Pedro River is considered to be one of many southwestern US fluvial systems that have undergone repeated cycles of arroyo cutting (i.e., rapid entrenchment and narrowing followed by widening/aggradation) in late Holocene time (Hereford \& Betancourt, 2009; Waters \& Haynes, 2001). The age of the most recent period of arroyo cutting/entrenchment is not precisely constrained but is generally considered to have occurred in the early part of the twentieth century based on extrapolating the increase in floodplain width over time documented in aerial photographs back to a presumed narrow state shortly following entrenchment (Hereford, 1993). Except for a few reaches where bedrock is exposed, the San Pedro River flows on modern postentrenchment alluvium located 1-10 $\mathrm{m}$ below an extensive series of Holocene terraces associated with earlier aggradation phases of the arroyo cycle (Cook et al., 2009; Onken et al., 2014; Pearthree \& Cook, 2015). The processes controlling the arroyo cycle in the southwestern United States generally and in the San Pedro River specifically are not fully understood but are generally thought, based on an analogy with discontinuous ephemeral streams, to involve feedbacks among channel width, slope, and aggradation in which aggradation facilitates floodplain widening, reduced sediment transport, and continued aggradation within "channel fan" regions of predominantly distributary flow until an oversteepened toe slope develops that is 


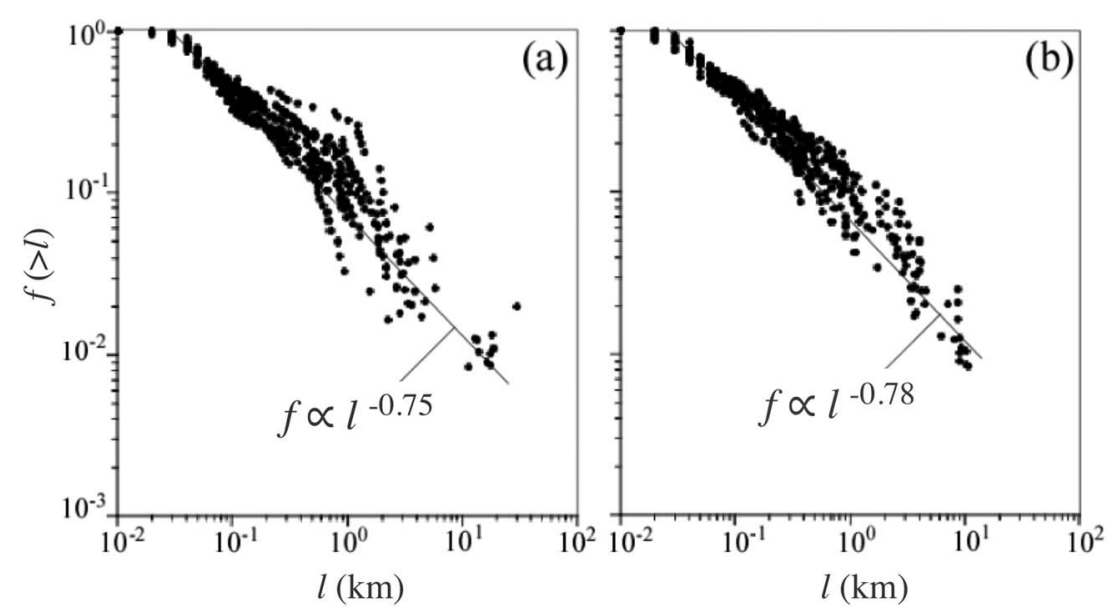

Figure 3. The cumulative frequency size distribution (normalized to 1) of the lengths of (a) wet and (b) dry reaches of the San Pedro River.

increasingly susceptible to rapid entrenchment and narrowing over time (Bull, 1997; Pelletier \& DeLong, 2005). Climate change and overgrazing have been proposed as potentially important reasons triggers that can modulate the periodicity of the arroyo cycle.

The Nature Conservancy in cooperation with the Bureau of Land Management and the Upper San Pedro Partnership has mapped the presence/absence of surface water flow along 900 10-m-long sections ( $\sim 90 \mathrm{~km}$ total) of the San Pedro River during the historically driest month (June) for over 10 years (Figure 1c). Figure 1d plots the frequency of wet years as a function of the distance along the channel. The channel is wettest in an $\sim 30-\mathrm{km}$ reach in the middle portion of the study region (i.e., "The Narrows") where the aquifer shallows and bedrock associated with the greater Tombstone Hills is exposed in the San Pedro River. The San Pedro River has the lowest frequency of observed wet years downstream of the Narrows and is intermediate in the frequency of wet years upstream from the Narrows. Approximately $32 \%$ of the total length of the study site exhibited year-round flow (Turner \& Richter, 2011) over the sampled years.

The cumulative frequency size distribution of wet and dry reach length $(l)$ are determined for each year from 1999-2008 (Figures 3a and 3b). These plots are constructed by ranking the lengths of wet and dry reaches from largest to smallest and plotting the rank divided by the total number of wet or dry reaches as a function of length. The data are consistent with a power law:

$$
f(>l) \propto l^{-m}
$$

with $m=0.77 \pm 0.11$. To better understand the significance of power law behavior in cumulative frequency size distributions, it is helpful to consider an analogy with the frequency size statistics of earthquakes. The Gutenberg-Richter Law states that the number of earthquakes larger than a given seismic moment decreases as a power law function of moment with an exponent of $\sim-0.7$ (Gutenberg \& Richter, 1956). Power laws are "heavy-tailed" functions in which the probability of a very large event, that is, one that is orders-ofmagnitude larger than the size of typical events, is relatively likely compared to an exponential or other "thin-tailed" distribution in which the probability of large events falls off relatively rapidly with increasing size. Power law frequency size distributions are common in geologic phenomena, including flood discharges (Malamud \& Turcotte, 2006), landslide areas (Pelletier et al., 1997), and wildfire areas (Malamud et al., 1998) in addition to earthquakes.

At the largest spatial scales along the San Pedro River (i.e., $>10 \mathrm{~km}$ ), the dominant control on the distribution of wet/dry reaches is "bottom up" (Figure 4a). Along-valley variations in DTB change the accommodation space for groundwater, forcing groundwater closer to or farther from the surface depending on whether the accommodation space is decreasing or increasing down-valley. Where the aquifer thins down-valley in this conceptual model, groundwater is transported toward the surface, promoting relatively wet surface conditions. Conversely, where the aquifer thickens down-valley, groundwater is transported away from the 

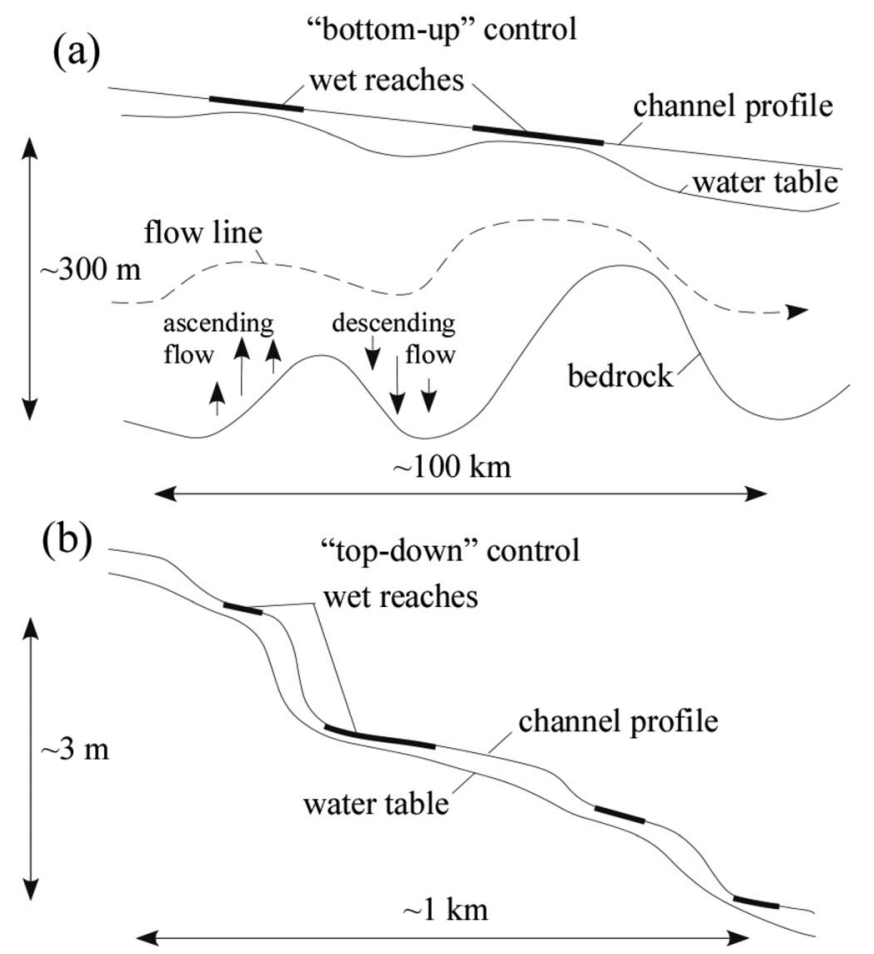

Figure 4. Schematic diagrams illustrating the conceptual models for (a) "bottom-up" and (b) "top-down" controls on depths to the water table. (a) At the largest spatial scales (i.e., $>10 \mathrm{~km}$ ), the dominant control on the distribution of wet/dry reaches is "bottom up", that is, along-valley variations in depth to bedrock change the accommodation space for water in the aquifer, forcing groundwater flow closer to the surface (promoting wet conditions) where the aquifer thins down-valley. Conversely, where the aquifer thickens down-valley, groundwater is diverted away from the surface, thereby promoting dry conditions. (b) At smaller spatial scales, the control of the distribution of wet/dry reaches in the San Pedro River is partly "top down"; that is, more incised reaches place groundwater closer to the surface, thereby promoting wetter conditions, all else being equal. surface, promoting relatively dry surface conditions. At smaller spatial scales the dominant control on the distribution of wet/dry reaches in the San Pedro River is “top down” (Figure 4b); that is, groundwater is closer to the surface along more incised reaches of the San Pedro River. A lower DWT promotes wetter conditions, all else being equal.

\subsection{Organization of Paper}

The remainder of this paper is organized as follows. We describe the methods and analysis of the relationships between hydrologic, geologic, and geomorphic variables that substantiate the bottom-up (Figure 4a) and top-down (Figure 4b) conceptual models in section 2 . In section 3, we present two numerical implementations of these conceptual models. Model results are presented in section 4 , which shows that the conceptual basis for the models are also physically plausible and in agreement with the data analysis of section 2. Discussion of the results and broader implications are described in section 5. Additional supporting figures and data are located in the supporting information.

\section{Analysis of Data}

In this section we present analysis of several available data sets for the San Pedro River and show how the data corroborate key assumptions of the conceptual models illustrated in Figures 4a and 4b. First, we discuss the methods and analysis for the statistical distribution of wet and dry reach lengths presented in section 2.1. It is then shown that downstream variations in frequency of wetness and DWT are anticorrelated. Analysis corroborating the bottom-up conceptual model is presented by comparing bedrock depth and water table depth. Then a similar analysis follows for the top-down model where we demonstrate a correlation between longitudinal channel slope and surface wetness along the San Pedro River. In the last section, we present analysis of temporal variations in alluvial channel bed elevation from alluvial streams located throughout the southwestern United States. The bed elevation data will be referenced later when we present analysis of our numerical model of the top down control.

\subsection{Cumulative Frequency Size Distribution of Wet and Dry Reach Lengths}

The ensemble average of the power law exponent $(\alpha)$ for all wet and dry reach length data is $m=0.77 \pm 0.11$. The ensemble average of $\alpha$ for wet reaches only is $0.75 \pm 0.09$ and for dry reaches only is $0.78 \pm 0.11$ (Figure 3). Parameter estimates were computed based on minimization of the Kolmogorov-Smirnov distance (Alstott et al., 2014). The validity of the power law fit was assessed by comparing the power law with alternative heavy-tailed distributions using the maximum likelihood ratio test (Clauset et al., 2009). Parameter estimates and test results are presented in Table 1, and individual wet and dry distributions are presented in the supporting information (Figures S1 and S2).

The power law fit was compared to the exponential, stretched-exponential, lognormal, and cutoff power law distributions (Table 1). Test results provide limited statistical support for the power law fit, meaning that while a power law fit is consistent with the data, three of the four alternative heavy-tailed distributions tested could not be conclusively ruled out. For comparison between the power law and exponential distribution, the power law was preferred $(R>0$ and $p<0.1)$ for 16 of the 20 tests, while the remaining tests were inconclusive $(p>0.1)$. For comparisons to the stretched exponential and lognormal distributions, all tests were inconclusive. For comparisons to the cutoff power law distribution, the cutoff power law was preferred over the power law for two tests $(R<0$ and $p<0.1)$ and inconclusive for the remaining tests. An inconclusive result for many of the tests is due to the small distribution sample size, where the average number of observations of wet or dry reach lengths at any given year was approximately 100. In practice, it is difficult to 
Table 1

The Estimated Power Law Parameters and Power Law Hypothesis Test Results for Wet and Dry Length Frequency Size Distributions Are Presented

\begin{tabular}{|c|c|c|c|c|c|c|c|c|c|c|c|c|c|}
\hline \multirow[b]{2}{*}{ Year } & & \multirow[b]{2}{*}{$\alpha$} & \multirow[b]{2}{*}{$\alpha_{\text {error }}$} & \multirow[b]{2}{*}{$D$} & \multirow{2}{*}{$\begin{array}{c}x_{\min } \\
(\mathrm{m})\end{array}$} & \multicolumn{2}{|c|}{ Exponential } & \multicolumn{2}{|c|}{ Stretched exp. } & \multicolumn{2}{|c|}{ Lognormal } & \multicolumn{2}{|c|}{ Power law + cutoff } \\
\hline & & & & & & $R$ & $p$ & $R$ & $p$ & $R$ & $p$ & $R$ & $p$ \\
\hline \multirow[t]{2}{*}{1999} & wet & 0.71 & 0.08 & 0.08 & 40 & 3.19 & 0.00 & 0.43 & 0.67 & -0.09 & 0.93 & -0.98 & 0.24 \\
\hline & dry & 0.99 & 0.11 & 0.05 & 40 & 2.63 & 0.01 & 0.97 & 0.33 & -1.18 & 0.24 & -0.37 & 0.80 \\
\hline \multirow[t]{2}{*}{2000} & wet & 0.78 & 0.09 & 0.07 & 40 & 2.4 & 0.02 & -0.08 & 0.94 & -0.37 & 0.71 & -0.76 & 0.4 \\
\hline & dry & 0.57 & 0.06 & 0.08 & 20 & 3.24 & 0.00 & -1.27 & 0.20 & -1.21 & 0.23 & -1.89 & 0.01 \\
\hline \multirow[t]{2}{*}{2001} & wet & 0.48 & 0.07 & 0.11 & 20 & 2.92 & 0.00 & -0.85 & 0.40 & -0.82 & 0.41 & -1.36 & 0.08 \\
\hline & dry & 0.76 & 0.13 & 0.1 & 50 & 2.48 & 0.01 & -0.11 & 0.92 & -0.29 & 0.77 & -0.81 & 0.37 \\
\hline \multirow[t]{2}{*}{2002} & wet & 0.74 & 0.07 & 0.07 & 30 & 2.66 & 0.01 & -0.27 & 0.79 & -0.48 & 0.63 & -0.98 & 0.20 \\
\hline & dry & 1.07 & 0.22 & 0.08 & 290 & 1.37 & 0.17 & 0.70 & 0.49 & -0.06 & 0.95 & 0.05 & 0.92 \\
\hline \multirow[t]{2}{*}{2003} & wet & 0.87 & 0.09 & 0.05 & 40 & 3.21 & 0.00 & 1.41 & 0.16 & -1.1 & 0.27 & -0.53 & 0.68 \\
\hline & dry & 0.83 & 0.09 & 0.08 & 40 & 1.60 & 0.11 & 0.85 & 0.40 & -0.03 & 0.97 & -0.23 & 0.42 \\
\hline \multirow[t]{2}{*}{2004} & wet & 0.80 & 0.08 & 0.08 & 30 & 3.7 & 0.00 & 1.38 & 0.17 & 0.14 & 0.89 & -0.67 & 0.57 \\
\hline & dry & 0.82 & 0.14 & 0.07 & 140 & 1.72 & 0.09 & 0.55 & 0.58 & 0.02 & 0.98 & 0.25 & 0.64 \\
\hline \multirow[t]{2}{*}{2005} & wet & 0.86 & 0.08 & 0.08 & 30 & 2.14 & 0.03 & 0.01 & 0.99 & -0.31 & 0.76 & -0.67 & 0.36 \\
\hline & dry & 0.75 & 0.09 & 0.07 & 70 & 1.97 & 0.05 & 0.42 & 0.67 & 0.07 & 0.95 & -0.55 & 0.28 \\
\hline \multirow[t]{2}{*}{2006} & wet & 0.58 & 0.07 & 0.10 & 20 & 3.17 & 0.00 & -0.73 & 0.47 & -0.75 & 0.46 & -1.41 & 0.07 \\
\hline & dry & 0.58 & 0.07 & 0.07 & 20 & 2.39 & 0.02 & 0.95 & 0.35 & -0.13 & 0.9 & -1.22 & 0.16 \\
\hline \multirow[t]{2}{*}{2007} & wet & 0.53 & 0.06 & 0.08 & 20 & 3.13 & 0.00 & -0.85 & 0.4 & -0.81 & 0.42 & -1.50 & 0.04 \\
\hline & dry & 0.94 & 0.17 & 0.11 & 170 & 1.5 & 0.13 & 0.21 & 0.83 & -0.92 & 0.36 & -0.01 & 0.98 \\
\hline \multirow[t]{2}{*}{2008} & wet & 1.11 & 0.27 & 0.08 & 40 & 1.62 & 0.12 & 0.18 & 0.86 & -0.03 & 0.97 & -0.37 & 0.72 \\
\hline & dry & 0.55 & 0.07 & 0.10 & 20 & 2.69 & 0.01 & 0.28 & 0.78 & 0.05 & 0.96 & 0.45 & 0.37 \\
\hline
\end{tabular}

Note. The power law exponent $(\alpha)$ and the associated error $\left(\alpha_{\text {error }}\right)$ are displayed for individual wet and dry reach length distributions for each year from 1999 to 2008. Parameter estimates are based on minimization of the Kolmogorov-Smirnov distance statistic $(D)$. The minimal starting value from which the power law fit may apply is $x_{\min }$. The validity of the power law fit was compared to several alternative heavy-tailed distributions via the log-likelihood ratio $(R)$ test. The $p$ value listed of each test is listed alongside $R$ and indicates if the sign of $R$ is statistically significant. The power law fit is preferred to the candidate distribution if $R>0$ and the sign of $R$ is statistically significant if $p<0.1$.

distinguish power laws from lognormal distributions and stretched-exponential distributions unless the sample sizes are exceptionally large (Malevergne et al., 2005; Clauset et al., 2009).

\subsection{Anticorrelation Between the Frequency of Wet Years and the DWT}

The conceptual model illustrated in Figure 4 rests on the assumption that the spatial distribution of wet/dry reaches is anticorrelated with water table depth, that is, that wetter surface conditions tend to occur in locations where the water table is shallow. To test this assumption for the San Pedro River, we first constructed a gridded map of water table depth using every available groundwater well from the U.S. Geological Survey's National Water Information System (U.S. Geological Survey, 2018) within the study region. For wells in which more than one groundwater depth was measured, depths were averaged over the period of record for that well. The resulting data set of well positions and time-averaged water table depth was then interpolated using Inverse-Distance-Weighting to obtain a gridded estimate of water table depth in the San Pedro River. The water table depth along the channel longitudinal profile was then extracted from this grid by traversing pixel-by-pixel along the same steepest-descent pathway used to extract the longitudinal profile from the DEM. A moving average filter with a length scale of $3 \mathrm{~km}$ was then applied to both series in order to honor the fact that spatial variations in water table depth at scales less than the typical spacing between wells (i.e., $\sim 3 \mathrm{~km}$ ) cannot be resolved. We then performed a Pearson correlation analysis between the water table depth profile and the number of wet years, resulting in a correlation coefficient $r$ and a $p$ value quantifying the likelihood of the null hypothesis that water table depth and wetness are unrelated.

Water table depth and the number of wet years from 1999-2008 are presented in Figure 5. There is a significant anticorrelation $\left(r=-0.44, p=4 \times 10^{-5}\right)$ for the southernmost $60 \mathrm{~km}$ of the study region. That anticorrelation breaks down within the Benson subregion where groundwater withdrawal for irrigation has historically been active (Cordova et al., 2013). Despite limitations in the data, especially the limited number of groundwater wells available to map DWT, this analysis corroborates a key assumption of the conceptual model illustrated in Figure 4 for most of the study region, that is, that a shallower water table tends to promote wet surface conditions. 

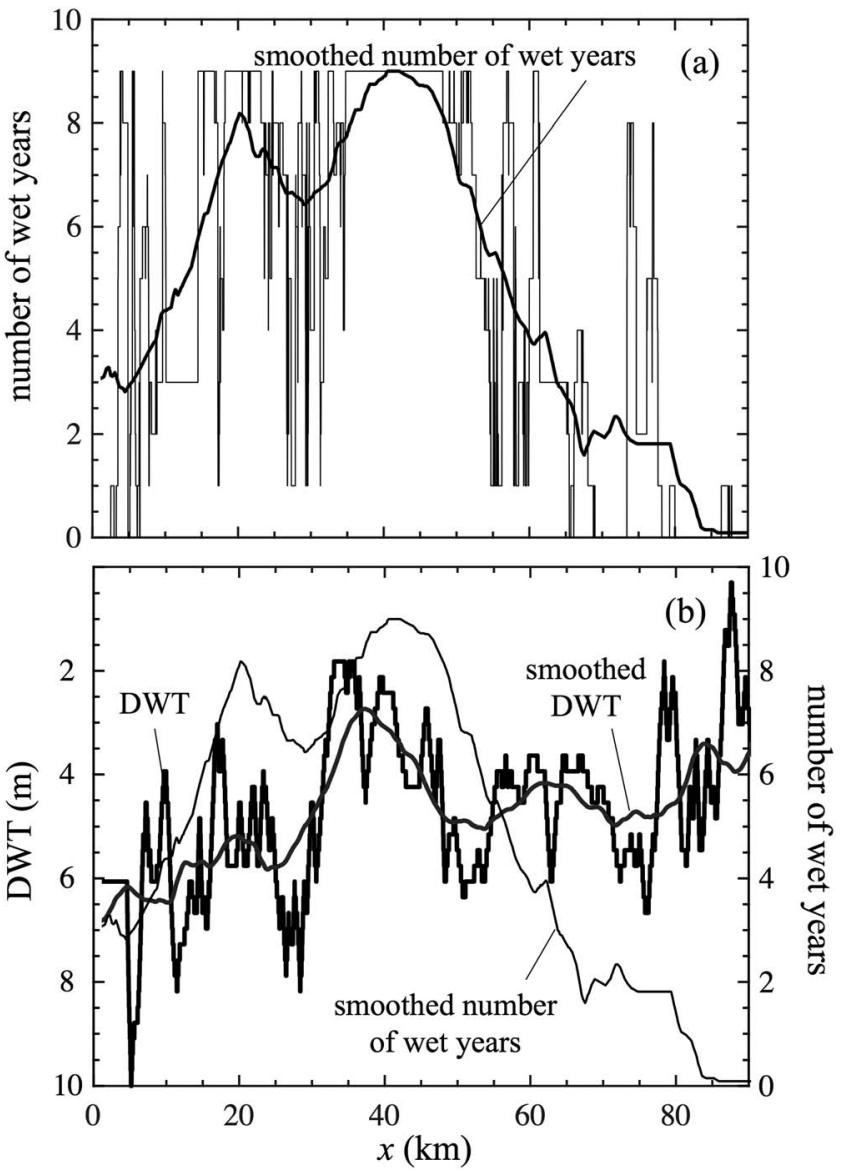

Figure 5. Surface wetness along the San Pedro River occurs where the water table intersects the channel bottom. This figure demonstrates the anticorrelation between the depth to the water table and the number of wet years at large spatial scales. Downstream follows increasing values of $x$ as in Figure 2a. (a) The number of wet years, including both raw data and the data with a 10-km moving-average filter applied. (b) Depth to the water table, smoothed water table depth (smoothed using the same moving average filter as in (a)) and the smoothed number of wet years.

\section{3. "Bottom-up" Control}

The conceptual model for a "bottom-up" control (Figure 4a) on surface wetness (and ultimately gaining and losing stream conditions) is based on the idea that surface wetness is influenced by variations in the subsurface flow accommodation space that force the groundwater table up toward, or down and away, from the channel surface. At large spatial scales, longitudinal variations in flow accommodation space are commensurate with longitudinal gradients in bedrock depth. To test whether this hypothesis is substantiated by data, we began with a grid of DTB for the study region extracted from Richard et al. (2007). The DTB along the channel longitudinal profile was then extracted by traversing the grid along the same pathway used to extract the longitudinal profile from the DEM and the DWT grid. We then computed the gradient of DTB along the profile to test the conceptual model that alongvalley gradients in DTB drive groundwater closer to, or farther from, the surface.

Longitudinal profiles of the bedrock depth and bedrock depth gradient along the San Pedro River are shown together in Figure 6a. The bedrock depth is large, that is, $\sim 1 \mathrm{~km}$, upstream and in the vicinity of Hereford. The bedrock depth is lower near Charleston and in the 30-km section between Charleston and Benson, then increases again downstream of Benson. Note that the gridded bedrock depth data do not resolve depth values less than $400 \mathrm{ft}(121 \mathrm{~m})$; hence, we have only maximum bedrock depth values for regions located approximately between Charleston and Benson. The number of wet years and the gradient of bedrock depth are shown to covary along the San Pedro River (Figure 6b). As in Figure 5, a moving-average filter has been applied to both series to focus the analysis on scales $>10 \mathrm{~km}$.

Based on this pattern of DTB data, together with the conceptual model illustrated in Figure 4a, we would expect that groundwater flowing longitudinally along the valley between the Mexico-USA border and Hereford to rise toward the surface in two pulses near kilometers 20 and 35. That is the pattern observed in the number of wet years (Figure 6b). Similarly, we would expect the number of wet years to decrease downstream of Benson as the accommodation space for groundwater increases. That pattern is also observed. A strong anticorrelation exists between the gradient of DTB and the number of wet years $\left(r=-0.76, p<10^{-6}\right)$.

\section{4. “Top-Down" Control}

The hypothesis that wet conditions are favored along relatively more incised reaches where the slope tends to be lower than average is conceptualized by Figure $4 \mathrm{~b}$. To test this conceptual model against data, we computed the correlation between the number of wet years and the channel gradient. We applied a moving average filter with a scale of $3 \mathrm{~km}$ to both series prior to performing a Pearson correlation analysis. Without such filtering, the channel slope computed at the highest resolution of the DEM is controlled by small-scale variations that in some cases may be dominated by errors in the lidar data set. Also, we focused our correlation test on the reach of the San Pedro River between Hereford and Charleston (i.e., distances of 15-35 km from the upstream end of the study region) to avoid portions of the profile that are continuously wet or nearly continuously dry. Large-scale, bottom-up controls on water table depth dominate in portions of the San Pedro River than are nearly wet or nearly dry over large distances. At these locations, because the number of wet years do not vary spatially, the channel gradient and number of wet years are clearly not correlated. In order to test for evidence of the top-down control, it is therefore necessary to focus on reaches of intermediate wetness. 

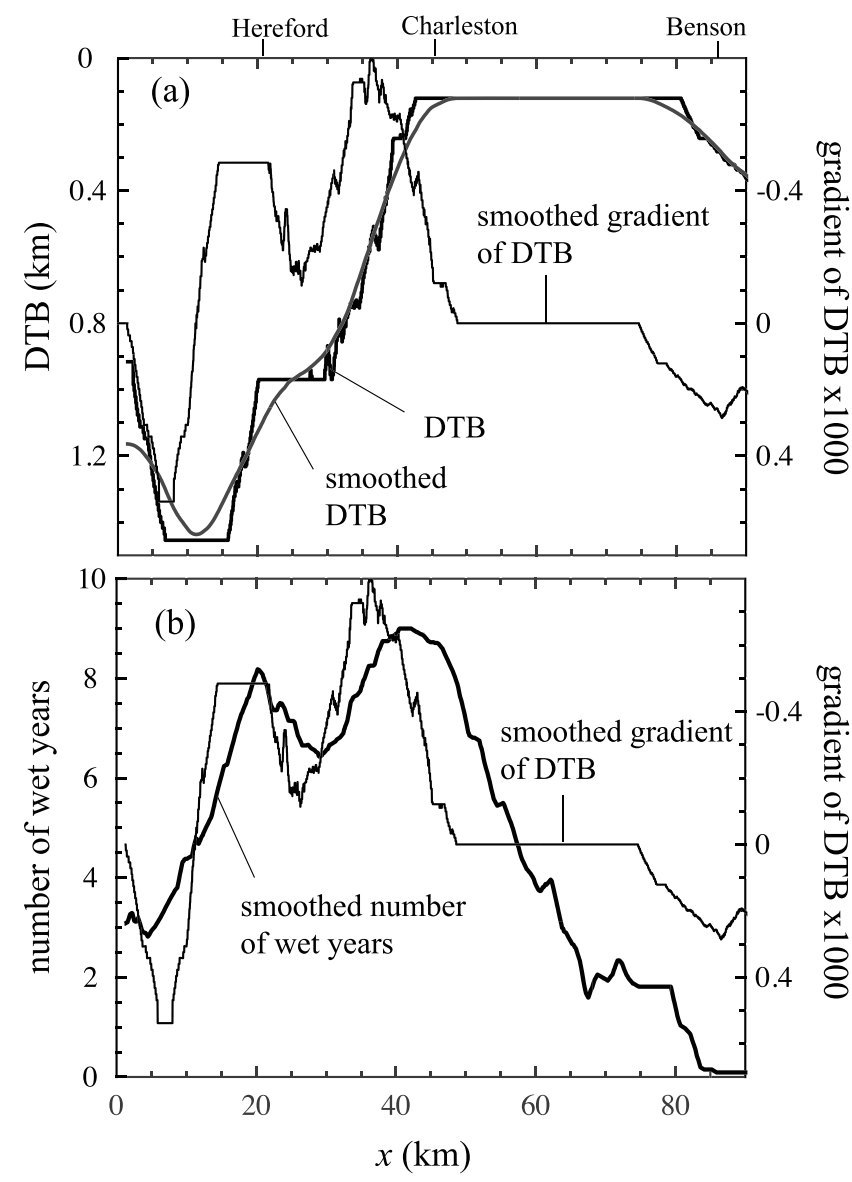

Figure 6. Gridded depth to bedrock and the smoothed gradient of depth to bed rock are shown in (a). The smoothed number of wet years and the smoothed gradient of depth to bedrock are shown in (b), where there is a strong anticorrelation in the gradient of depth to bedrock, and the number of wet years is consistent with the bottom-up conceptual model in Figure 4a.

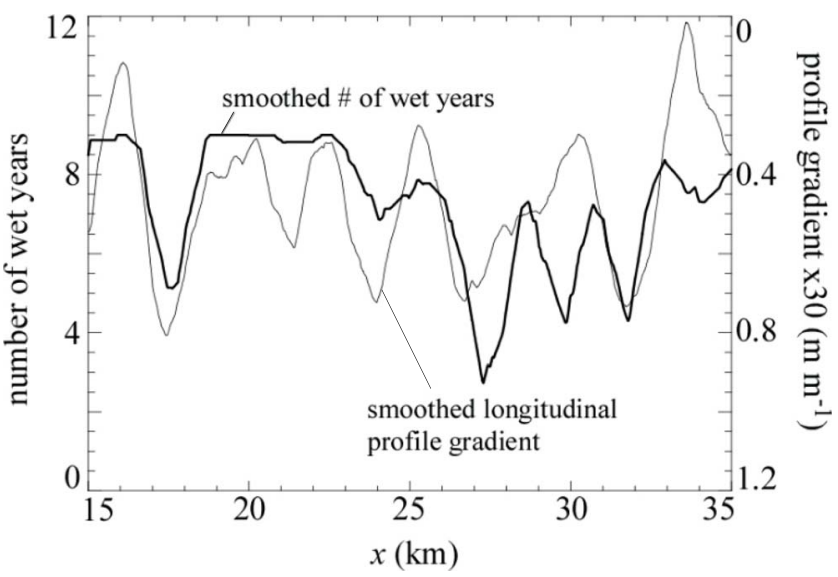

Figure 7. The number of wet years and channel slope along the San Pedro River are shown together. Both series have been smoothed (a movingaverage filter has been applied) over a length scale of $3 \mathrm{~km}$. This plot demonstrates an anticorrelation between channel slope and the number of wet years consistent with the top-down conceptual model in Figure $4 \mathrm{~b}$.
Figure 7 plots the channel slope and the number of wet years for the portion of the San Pedro River between $x=15$ and $35 \mathrm{~km}$. Increases in channel slope are associated with decreases in the number of wet years at $x \approx$ $17,24,27$, and $32 \mathrm{~km}$. Over the length from $x=15$ to $35 \mathrm{~km}$, a Pearson correlation analysis indicates the null hypothesis that the two variables that are unrelated can be rejected with a high probability $\left(r=0.24, p<10^{-6}\right)$. The correlation coefficient is not as strong as that for bottom-up control, suggesting that top-down control is not as strong an influence on the surface hydrologic state of the San Pedro River.

\subsection{Self-Affine Temporal Variations in Channel Elevation}

A numerical model for demonstrating alluvial channel longitudinal profiles described later (section 3.3), generates temporal variations in channel bed elevation that are self-affine. In order to test this prediction against data, we compiled and analyzed time series for the so-called adjustment parameter for all 88 gaging stations for which channel adjustment data are available. These stations are located throughout Arizona, California, Nevada, New Mexico, Utah, and Wyoming (U.S. Geological Survey, 2016). The U.S. Geological Survey uses adjustment parameters (units of length) to adjust stage data for the average aggradation/incision of the wetted perimeter. As such, adjustment parameters record changes in the channel bed elevation, averaged across the channel cross section, as a function of time (Juracek and Fitzpatrick, 2009).

To obtain spectra of bed elevation through time, each time series of the adjustment parameter is first resampled to an evenly spaced time interval. Time series were integrated to obtain channel elevation as a function of time from which the power spectrum of bed elevation for each station was then estimated. Individual estimates were averaged together for each frequency across all gages to obtain an average power spectrum of temporal variations in the bed elevation of dryland alluvial channels. The average power spectrum for the channel adjustment factor at 88 U.S. Geological Survey stream gaging stations is found to be proportional to $f^{-1.5}$ (Figure 8). This implies that fractal self-affine temporal variations in bed elevation are likely a general characteristic of southwest alluvial channels.

\section{Modeling}

The models presented here complements existing studies that emphasize the spatiotemporal complexity of alluvial rivers, including several studies that have emphasized their fractal or multifractal properties. For example, Sapozhnikov and Foufoula-Georgiou (1997) emphasized the fractal aspects of the planform morphology of braided rivers. The cellular automaton model presented here shares basic attributes (e.g., slopedependent transport, stochastic entrainment) with the model that Murray and Paola (1994) proposed for braided rivers. The stochastic sediment transport model we present is a discrete version of a class of stochastic Langevin models that have been used successfully to capture aspects of the episodicity of sediment transport in alluvial channels (e.g., Fan et al., 2016).

\subsection{Fractional Brownian Motion Domains of Exceedance}

One way that a power law frequency size distribution can occur is in association with the extreme values of a fBm. Figure 9a illustrates this concept 


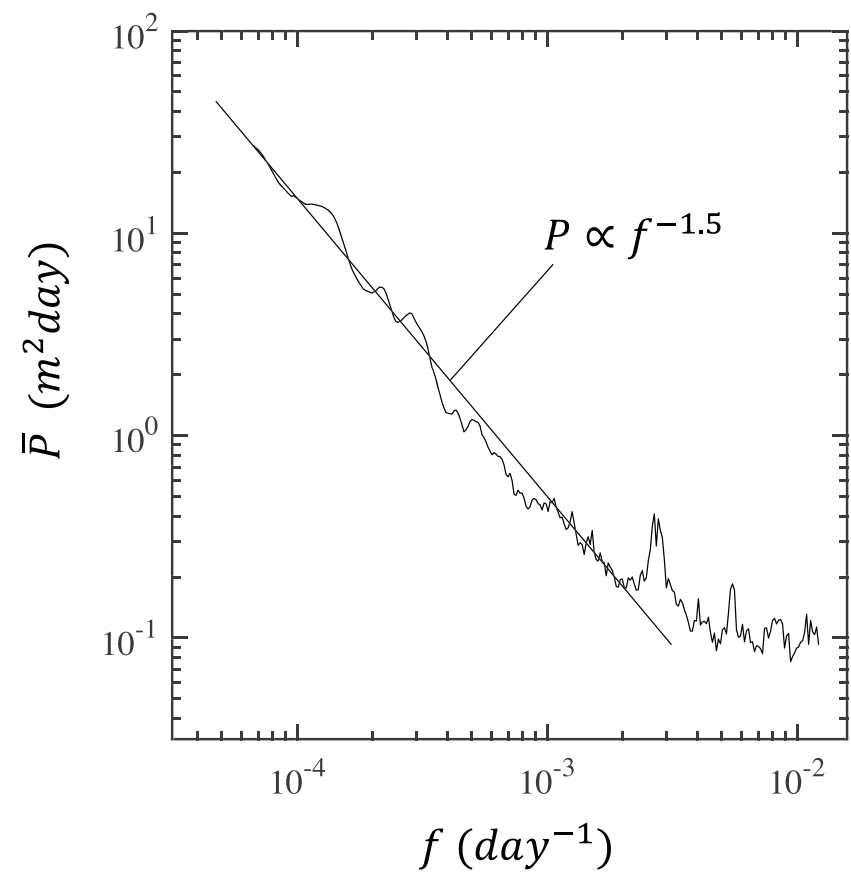

Figure 8. The average frequency $(f)$ power spectrum $P$ of bed elevation at a point in space through time for 88 USGS gauging stations. The black line indicates the best fit line to the power pectrum after a log-log transformation of the axes. The region of the power spectrum fit indicates that power scales in proportion to $f^{-1.5}$. using a $\mathrm{fBm}$ with $\beta=1.8$. The domains where the $\mathrm{fBm}$ exceeds a threshold value (e.g., 1.5 is used as an example in Figure 9a) take on a wide range of lengths. The cumulative frequency size distribution of these domains is a power law. For example, Figure 9b plots five samples of $\mathrm{fBm}$ with $\beta=1.8$. These examples have been constructed by Fourier-filtering a Gaussian white noise and rescaling the result so that the series have a mean of zero and standard deviation of 1 . Figure 9c plots the cumulative frequency size distribution of the domains of $100 \mathrm{fBm}$ in which a prescribed threshold is exceeded. Two frequency size distributions are plotted: one corresponding to a threshold value of 2 and another with a threshold value of 2.5 . The cumulative frequency size distribution follows equation (2) with $m=0.8$ for both threshold values.

If wet reaches of the San Pedro River represent domains where the longitudinal profile has excursions above or below some threshold value, Figure 9 demonstrates that it is possible for the cumulative frequency size distribution of such reaches to be a power law with an exponent similar to that in Figure 3. Pelletier et al. (1997) applied a similar threshold-based concept to understanding the relationship between the frequency size distribution of shallow landslides and self-affine variations in soil moisture, which can trigger landslides via elevated pore pressure. Pelletier et al. (1997) demonstrated that soil moisture data from the Washita experimental watershed was consistent with a fBm with $\beta=1.8$. These authors then argued that, for hillslopes of otherwise similar steepness and other conditions affecting slope stability, domains that were susceptible to landsliding corresponded to areas in which the soil moisture was above a threshold value. The result was an explicit linkage between the power spectral properties of a primary control on hillslope stability (i.e., soil moisture) and the frequency size statistics of landslides.

The data analysis results in section 2 demonstrate the plausibility of a bottom-up and top-down control on hydrology. In sections 3.2 and 3.3 we develop numerical models to show that these conceptual models are physically realistic. Ultimately, these models will be used to demonstrate how spatially self-affine hydrology (Figure 3) is linked to spatially self-affine surface (Figure 2c) and subsurface morphology through analogy with the threshold exceedance domains of a fBm (Figure 9).

\section{2. "Bottom-up" Control}

To demonstrate how along-valley gradients in DTB can drive spatial variations in the DWT, we modeled the height of the water table above bedrock, $h$, using the two-dimensional Boussinesq model for the water table in an unconfined aquifer bounded below by a bedrock surface $z_{\mathrm{b}}$ (e.g., Turcotte \& Schubert, 2002):

$$
\frac{\partial h}{\partial t}=\frac{k \rho g}{\mu \phi} \frac{\partial}{\partial x}\left(h\left(\frac{\partial h}{\partial x}+\frac{\partial z_{\mathrm{b}}}{\partial x}\right)\right)+R
$$

where $t$ is time, $k$ is the hydrologic conductivity, $\rho$ is the density of water, $g$ is the acceleration due to gravity, $k$ is the viscosity of water, $\phi$ is porosity, $x$ is the along-valley distance, and $R$ is the net recharge. Assuming a steady state balance between net recharge and the divergence of lateral groundwater flow, the Boussinesq equation becomes

$$
h\left(\frac{\partial h}{\partial x}+\frac{\partial z_{\mathrm{b}}}{\partial x}\right)=c
$$

where $c$ is a constant (unit of length) that combines the influence of $k, \rho, g, \mu, \phi$, and $R$. The value of $c$ was varied to obtain a "family" of potential water tables corresponding to a range of recharge scenarios and aquifer characteristics. Equation (4) is identical to the equation for the shape of gravity flows (e.g., alpine glaciers) in the perfectly plastic limit. Equation (4) was solved using the "sandpile" algorithm that Palmer et al. (2008) 

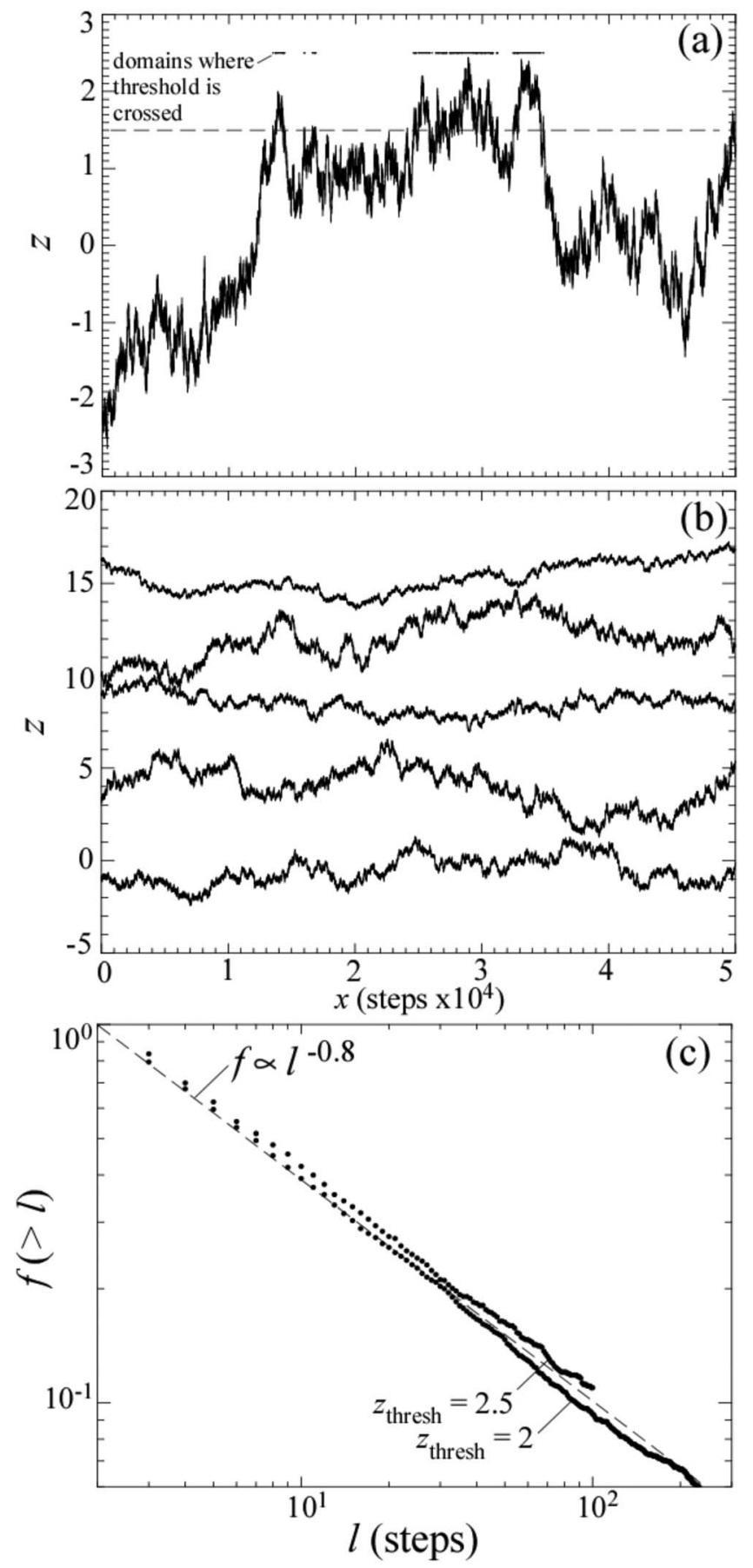

Figure 9. The domains of exceedance of a fractional Brownian motion $(\mathrm{fBm})$ have a cumulative power law frequency size distribution. Domains of exceedance are also referred to in different literatures as level crossing sets, zero-crossing sets, and the Telegraph approximation. (a) Illustration of the concept of domains of exceedance. Domains in which the $\mathrm{fBm}$ is above a threshold value $\left(z_{\text {thresh }}=1.5\right.$ in this example) are shown near the top of the plot. The distributions in (c) quantify the range of continuous lengths where $z$ is above $z_{\text {thresh }}$. (b) Five example realizations of a fBm with $\beta=1.8$. (c) Plot of the frequency size distribution of 1,000 realizations of a fBm with $\beta=1.8$ for two values of $z_{\text {thresh }}: 2$ and 2.5. Both distributions are consistent with $f \propto l^{-0.8}$. originally developed for perfectly plastic flows but that can also be used to solve equation (4) for any application, including the shape of the water table above a variable bedrock surface. In the sandpile algorithm, $h$ at each grid point is initially zero and is then incremented in small discrete steps until the product of the height of the water table above bedrock and the slope of the water table is equal to $c$. A value for $h$ at the downstream boundary of the grid must be prescribed (here we assume zero). For the purposes of this modeling exercise, we took the bedrock elevation profile to be a $\mathrm{fBm}$ with $\beta=1.8$. We do not have DTB data of sufficient resolution to test this hypothesis, but data for DTB (Figure 6) demonstrate that DTB in San Pedro River has multiscale variability and are nonstationary, that is, $\beta>1$; hence, they are consistent with a $\mathrm{fBm}$.

\section{3. "Top-Down" Control}

In order to understand how self-affine fractal variability can develop in alluvial channel longitudinal profiles, we developed a model for alluvial channel profile evolution based on the conservative slope-dependent transport of discrete units or "blocks" of sediment. This model is similar to classic cellular automaton models that have been developed for other geomorphologic systems, including the dune model of Werner (1995), the braided river model of Murray and Paola (1994), and the bank retreat model of Fonstad and Marcus (2003), just to name a few.

At each time step of the model (defined as one storm), a pixel is chosen at random as the location of a storm capable of transporting sediment. The storm size, that is, the number of discrete sediment units that will be transported from that location downstream during the time step, is drawn from a zeta distribution (i.e., the integer version of a power law distribution):

$$
p(n=M)=\frac{1}{\zeta(a)} M^{-a}
$$

where $\zeta(a)$ is the Zeta function. We use a Zeta distribution to honor the fact that large flood discharges often have a power law distribution (Malamud \& Turcotte, 2006; Turcotte \& Greene, 1993). The transport of a unit of sediment along the channel is controlled by two parameters: a slope-dependent entrainment threshold $\left(s_{t}\right)$ and slope-dependent deposition threshold $\left(s_{d}\right)$. The units of slope are equal to the thickness of one discrete unit of sediment $(\Delta z)$ divided by one pixel length $(\Delta x)$. If the channel slope at the chosen site is greater than the entrainment threshold, that is,

$$
s\left(x_{i}\right)>s_{t}
$$

then a unit of sediment is moved downstream to the first site where the criterion for deposition is met, that is,

$$
s\left(x_{j}\right)<s_{d}
$$

where the subscript $j$ is used to indicate that the site $x_{j}$ is downstream of $x_{i}$. This process is repeated until the total number of sediment units transported downstream is equal to $n$. If the initial site $x_{i}$ ceases to meet the entrainment threshold and $n$ units of sediment have not been moved, the first site downstream of $x_{i}$ that satisfies equation (6) is assigned to be the new entrainment location. The initial condition for the model is a 


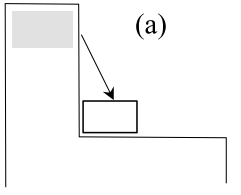

local erosion local deposition

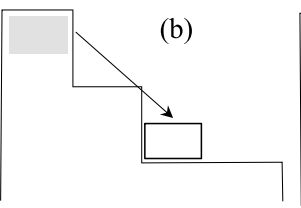

local erosion downstream deposition

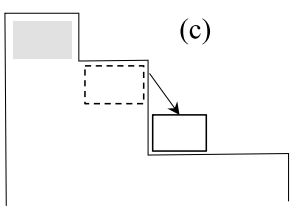

downstream erosion local deposition

Figure 10. Schematic diagram of erosion and deposition rules in the numerical model for alluvial channel evolution. The gray filled box indicates the location of a storm site. The arrow begins at the pixel where sediment is eroded and ends at the unfilled box where the sediment is deposited. (a) Sediment is moved one site downstream, because the slope at the storm site exceeds the erosion threshold slope, and the next site down is less than the deposition threshold. (b) Erosion occurs at the first site, but the next site downstream exceeds the deposition threshold. Sediment is deposited two sites downstream where deposition criterion is met. (c) The slope at the storm site does not exceed the erosion threshold. The next site downstream does, so the arrow indicates that sediment is removed from the second site (rather than the storm site), and moves one site downstream of the erosion site (where the slope is less than the deposition threshold).

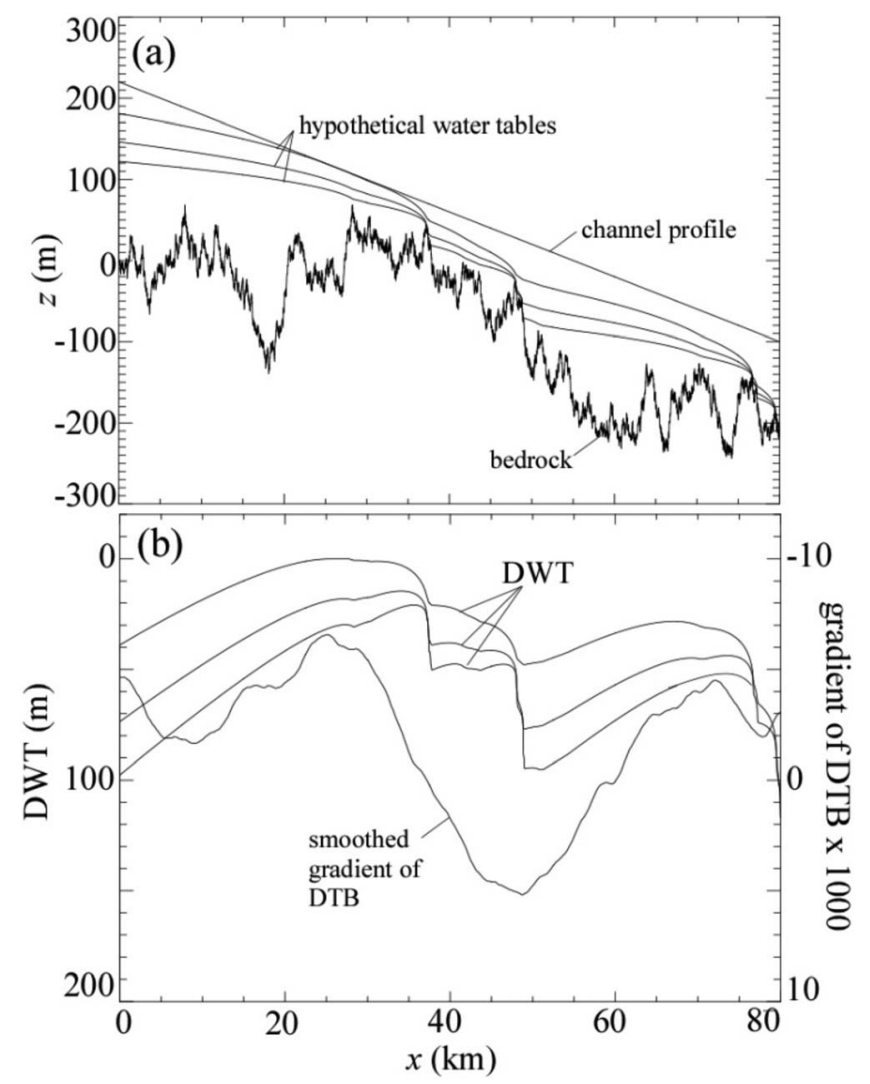

Figure 11. The bottom-up model is implemented numerically based on the Boussinesq equation for the water table in an unconfined aquifer. A bedrock depth profile shown in (a) is a $\mathrm{fBm}$ with $\beta=1.8$ superposed upon a linear trend. Solutions to the Boussinesq equation result in a family of water table solutions, from which three water table profiles are shown in (a). In (b), the smoothed gradient of depth to bedrock (DTB; corresponding to Figure 11a) is shown in comparison to three depth to water table (DWT) profiles (corresponding to Figure 11a). Panel (b) demonstrates the correlation between the gradient of DTB and DWT. linear profile with slope $s_{\text {avg. }}$. The basic model rules are depicted in Figure 10.

To relate spatial variations in the alluvial channel evolution model into spatial variations in surface water hydrology, we represent the groundwater table as a straight line parallel to the linear trend of the longitudinal profile. This represents the situation where topography exerts only a passive control on the water table by following the large-scale relief (as in low relief topography and arid valleys). Wet-dry time series $w(x)$ are generated based on the alluvial channel model as follows. The water table lies at some depth, sloping parallel to the elevation profile. The water table depth, $D(x)$, is the difference between $z(x)$ and the water table (i.e., $D(x)=z_{d}(x)$ up to a constant). To obtain $w(x)$ for a given profile, a threshold depth $(d)$ determines if location is wet. If $D(x)>d$, then $w(x)=1$ and vice versa. The value of $d$ is determined by first specifying a wet fraction, defined as the number of wet cells divided by the total number of cells. Then $d$ is the depth that results in a given wet fraction along the entire domain. For a given channel profile output by the model, $d$ is varied to obtain multiple realizations of $w(x)$ yielding wet-dry profiles with a range of total fraction wet similar to the range observed across the 10 years of wet-dry data for the San Pedro River.

\section{Model Results}

\section{1. "Bottom-up" Control}

Example output of the Boussinesq equation model for a flow through an unbounded aquifer above a hypothetical $\mathrm{fBm}$ bedrock surface with $\beta=1.8$ are presented in Figure 11. Figure 11a plots three variables: channel bed elevation $(z)$, bedrock elevation $\left(z_{\mathrm{b}}\right)$, and the modeled water table obtained by solving equation (4) for $c=0.05,0.1$, and 0.2 $\mathrm{m}$. For the purposes of this model exercise, the channel profile is assumed to be linear. This is a reasonable approximation in this context given that the deviations from a linear profile in San Pedro River are 2 orders of magnitude smaller (i.e., $\sim 10 \mathrm{~m}$ ) than deviations in bedrock elevation $(\sim 1 \mathrm{~km})$. As such, spatial variations in DTB are dominated by variations in bedrock elevation. The results of Figure 11 demonstrates that the water table tends to approach the surface above reaches where the bedrock is shallowing down-valley, and tends to move away from the surface where the bedrock is deepening down-valley. Figure 11b presents model predictions for the gradient of DTB and the DWT, both with a moving-average filter of $10 \mathrm{~km}$ applied to the model predictions so that they can be compared with similarly smoothed versions of the data. Figure 11b demonstrates that the model predicts a similar correlation between the large-scale gradient of DTB and water table depth (i.e., $r=0.4-0.5$, depending on the value of $c$ ) and observed in data (i.e., the data exhibit an anticorrelation between the gradient of DTB and the number of wet years, which together with the anticorrelation of the number of wet years and DWT are consistent with a positive correlation between DTB and DWT).

\section{2. "Top-Down" Control}

The alluvial channel model behavior is qualitatively similar for a wide range of values for $s_{d}$ and $s_{t}$ provided that $s_{t}<s_{\text {avg }}<s_{d}$. The results presented here correspond to $L=1,024, s_{\mathrm{t}}=10, s_{\mathrm{avg}}=50$, and $s_{\mathrm{d}}=100$. We 


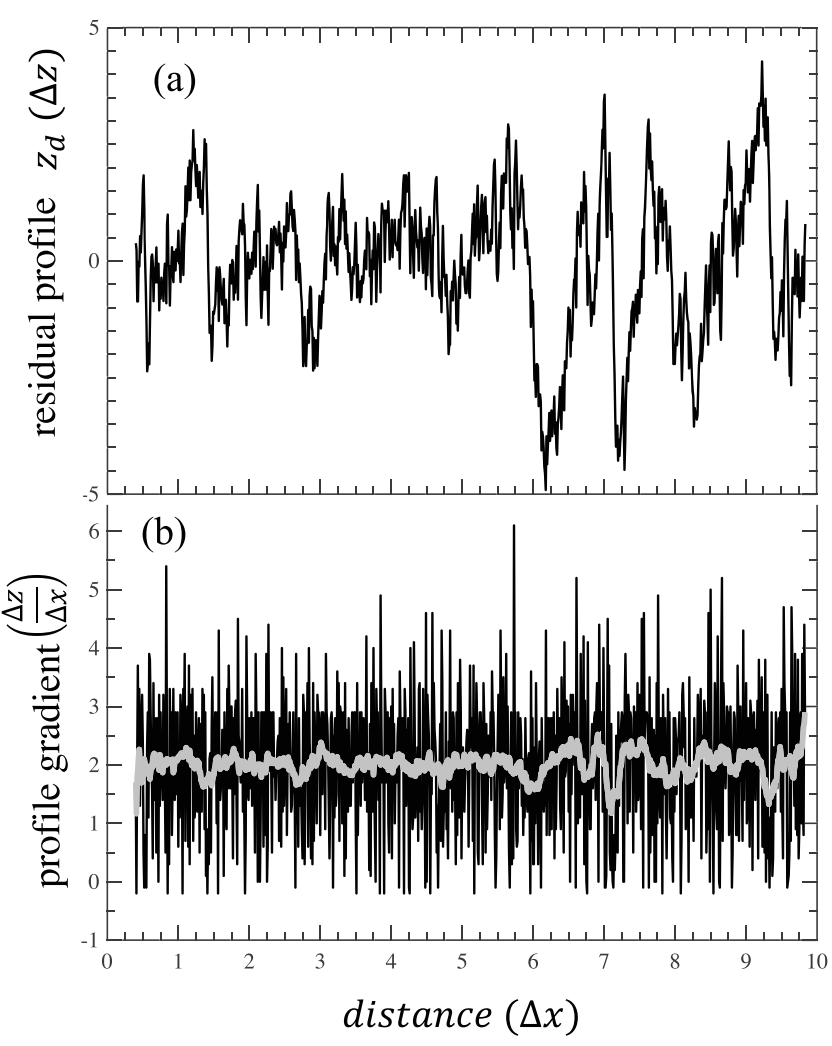

Figure 12. Example alluvial channel model output corresponding to one model realization of a longitudinal channel profile. (a) The detrended elevation profile, and (b) the corresponding profile gradient (black) and average profile gradient using a 20-point moving average (gray). chose this set of values because larger $s_{d}$ and $s_{t}$ values require more time to reach a dynamic steady state, while values that are sufficiently small result in profiles with fluctuations from a linear profile that approach the thickness of one unit of sediment. For the storm size distribution, we chose $\zeta=2.3$, similar to values obtained by Turcotte and Greene (1993) and Malamud and Turcotte (2006).

One typical example of the model output is shown in Figure 12a where the detrended profile is shown after $5 \times 10^{4}$ time steps. Figure $12 \mathrm{~b}$ shows the slope (black) and the slope smoothed using a 20-pixel moving average filter (gray). The power spectrum of the detrended profile (Figure 12a) is shown in Figure 13a. A linear regression of the spectrum in Figure 13a indicates the slope scales as $v^{-1.7}$. This value is consistent across all values of storm exponents tested (2.3 to 2.7) and is not sensitive to specific choices of threshold slopes. The power spectrum of elevation changes at a point in space through time for the alluvial channel model is shown in Figure 13b for a single model run. A linear-regression of the power spectrum estimates that power scales with frequency approximately as $f^{-1.4}$, while the average across several model realizations is approximately $f^{-1.5}$. This result was not found to be sensitive to variations in threshold slope parameters.

The model frequency and wave number spectra show the alluvial channel model is characterized by fractal self-affine spatial and temporal variability. These are fundamental attributes resulting from the model dynamics in combination with stochastic forcing (though not sensitively dependent to the distribution parameters). The model elevation spectrum is consistent with the power spectrum of the detrended elevation profile of the San Pedro River (Figure 2c) at scales less than $\sim 10 \mathrm{~km}$. While we could not explicitly compare the modeled bed elevation spectra to the San Pedro River, these closely match the bed elevation spectra for other southwest alluvial channels (Figure 8).

\subsection{Model Comparison to Wet-Dry Data}

The gray line in Figure 14 shows $w(x)$ corresponding to a wet fraction of 0.7 (70\% wet). The channel gradient is smoothed by a 20-point linear fit and overlaid (black). Channel gradient correlates with $w(x)$ (cf. Figure 7). Where the channel gradient is high corresponds to dry reaches, and where the channel gradient is low corresponds to wet reaches. This illustrates a top-down control of topography on the surface expression of groundwater (as in Figure 4b).

The exceedance probability $f(>l)$ of wet and dry lengths displayed in Figure 14 are shown in Figure 15. The solid black circles correspond with the wet series $w(x)$ and the gray circles correspond with the dry series $(1-w(x))$. The exceedance probabilities are power law for both wet and dry series, with exponents equal to 0.81 and 0.77 , respectively. The exponents are calculated based on the method of maximum likelihood for estimating power laws in empirical data (Clauset et al., 2009).

The model produces a range of exponents with ensemble average close to $m=0.8$ for both wet and dry reaches (Figure S3). Year to year variation in modeled $m$ is a function of the total fraction wet, and this is also observed in the data (Figure S4). This suggests that variations in observed scaling exponents could result from year to year differences in average groundwater inputs to aquifer system. This dynamic reflects the fractal nature of the model: a reach of arbitrary length does not dry out simultaneously, but instead can be viewed as a progressive fractal fragmentation process whereby a reach differentiates into progressively smaller wet reaches.

The modeling results together suggest the fractal scaling of wet and dry reach length frequency statistics is a direct manifestation of the fractal self-affine spatial variability in bedrock depth and channel elevation. This can be understood through analogy to threshold domains of exceedance in a fraction Brownian motion 

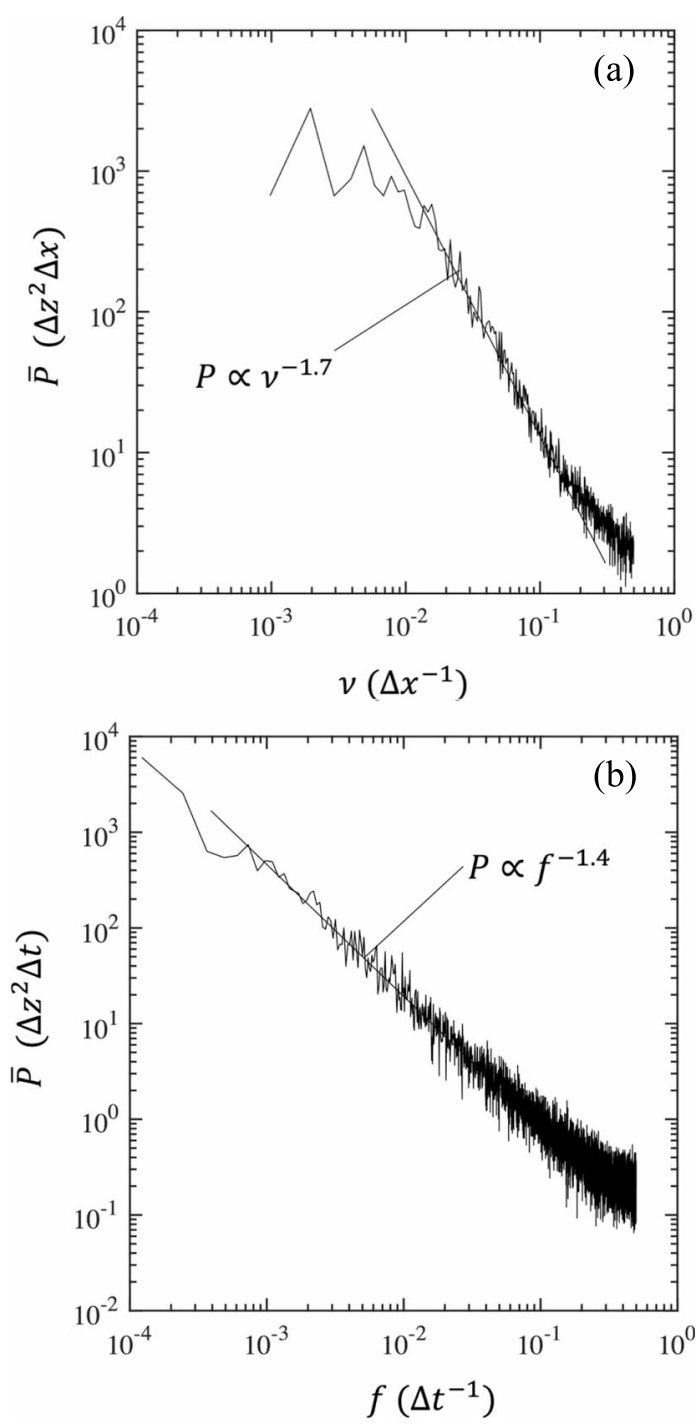

Figure 13. Spectral analysis of the scaling behavior in output from the alluvial channel model. (a) Wave number power spectrum of the residual profile. (b) Frequency power spectrum of bed elevation fluctuations at a point space through. Spectra shown were estimated by averaging across 10 realizations of the channel profile. (section 3.1). In this analogy, the exponent $m$ of the power law cumulative frequency size distribution (equation (2)) is directly related to the exponent $\beta$ of the power law wave number power spectrum (equation (1)). The nature of this relationship is discussed futher in section 5.4.

\section{Discussion}

Within the Basin and Range province that is home to many dryland U.S. fluvial systems, large-scale ( $>\sim 10 \mathrm{~km}$ ) longitudinal profile variability is partly the result of spatial variability in tectonic activity (i.e., uplift/subsidence rates and their spatial and temporal variability). Dominant range-bounding faults in the Basin and Range are generally separated by distances of less than or equal to the dominant wavelength of 25-60 km (Fletcher \& Hallet, 1983). Uplift or subsidence occurs on many faults that are subsidiary to range-bounding faults, and activity is likely to be temporally complex, with clustering and/or anticlustering of uplift events over a range of temporal scales. Sediment transport is driven by groundwater discharge and episodic runoff events that can also be highly variable in space and time. A fundamental question this work addresses is as follows: What is the impact of the pulsed nature of tectonic activity and sediment transport events on the multiscale spatial and temporal variability observed in alluvial channel longitudinal profiles and depth-to-bedrock profiles, and what is the impact of such variability on hydrology?

\subsection{Comparison With Published Literature on San Pedro River Hydrology}

Our results complement published conceptual models for the hydrogeology of the San Pedro River. Previous studies have argued that the thinning of the aquifer down-valley upstream of the Narrows forces groundwater flows toward the surface, leading to wetter surface conditions at that location (e.g., Cordova et al., 2013; Pool \& Coes, 1999). This paper places that conceptual model within a quantitative framework via the Boussinesq model for the water table above a variable bedrock surface. The model predicts an anticorrelation between the gradient of DTB and wet surface conditions similar to that observed in data. Our work also complements the results of Baillie et al. (2007), who quantified the relative contributions of monsoon recharge and groundwater to surface flow. These authors found that flows in wetter reaches are dominated by old groundwater transported long distances from regional highlands, while drier reaches are dominated by infiltration associated with recent precipitation events. This paper demonstrates the bottom-up (i.e., hydrogeologic) and top-down (i.e., geomorphic) processes that control the spatial distribution of dominant hydrologic source types documented by Baillie et al. (2007).

\subsection{Comparison to Alterative Models of Dryland Rivers}

The results of this paper provide a useful counterpoint to studies that view dryland river systems as simple (e.g., Singer and Michaelides, 2014). The longitudinal profile of the San Pedro River certainly has a firstorder linear trend, one that likely reflects the river's evolution to an approximately graded system in which sediment supply and transport are in balance over time scales of $\sim 10^{6}$ years. However, the residual profile of the San Pedro River has significant complexity, likely influenced by both spatial variations in DTB and the episodicity of sediment transport. Our model does not explicitly include cycles of arroyo cutting and filling. Including the arroyo cycles that have been documented along the San Pedro River and other dryland systems of the southwestern United States would add additional richness to the already complex nature of the San Pedro River and similar dryland alluvial river systems. 


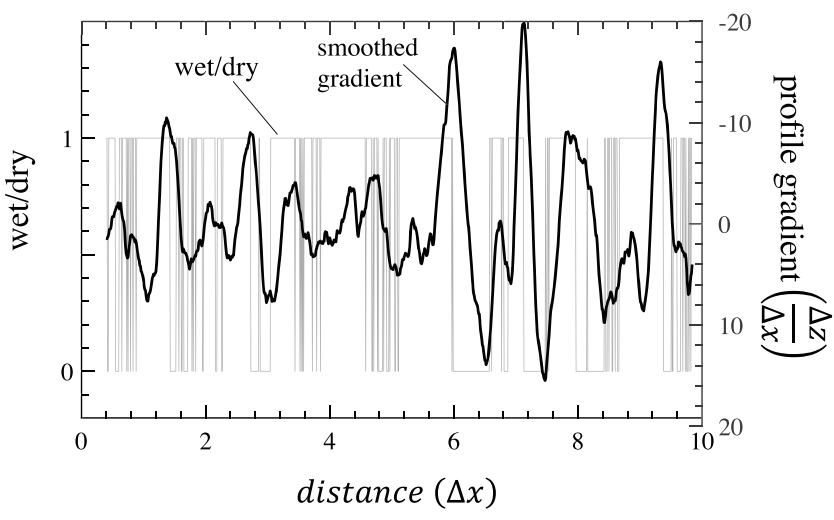

Figure 14. Example output from the alluvial channel model showing a wetdry record (taking values of 1 (wet) and 0 (dry)) depicted as the gray line. The smoothed channel slope is overlaid in black.

\subsection{Power Law Distribution of Wet and Dry Reach Lengths}

Identification of power laws in empirical data sets has been the subject of debate for several decades (e.g., White et al., 2008). Several methods commonly used to quantify power law distributions such as Hill's estimator (Hill, 1975), or a linear regression of log-transformed distributions, are in most cases outperformed by more sophisticated statistical procedures such as maximum likelihood-based methods (Bauke, 2007). An additional issue is whether the power law model provides the best fit in comparison to other heavy-tailed distributions, for which a range of model comparison methods exist (Clauset et al., 2009). A subset of these statistical methods have been applied to the wet and dry reach length distributions (Figure 3) to test the validity of a power law fit to wet and dry reach length distributions (section 2.1 and Table 1). The individual sample sizes for any given year is unfortunately too small. The model comparison tests are in most cases inconclusive, aside from the exponential distribution, which provides a conclusively inferior fit to the power law.

In complex systems, power law distributions are diagnostic and should be taken as proxies for more interesting underlying system dynamics (e.g., long-range spatial or temporal correlations). The San Pedro River meets the definition of a complex system (Werner, 1999) because it is dissipative, open, driven by nonlinearities in the form of transport thresholds, and is subject to highly episodic multiscale environmental forcing. In our study, we have provided evidence of self-affine scaling in channel elevation as a function of space (Figure 2c) for the San Pedro River, and in the channel elevation fluctuations at a point in space as a function time for Southwestern United States arid streams generally (Figure 8). Figure S5a shows the wave number power spectrum of wet-dry signals as a function of longitudinal position along the channel, where a wet reach has a value of 1 and dry reach has a value of 0 . The power-spectrum is self-affine where power scales proportional to $v^{-1.23}$. In Figure S5b, the same analysis was performed on artificially generated domains of exceedance (see Figure 9a). For a direct comparison to the wave number spectrum of San Pedro river data and modeling results, we chose the frac-

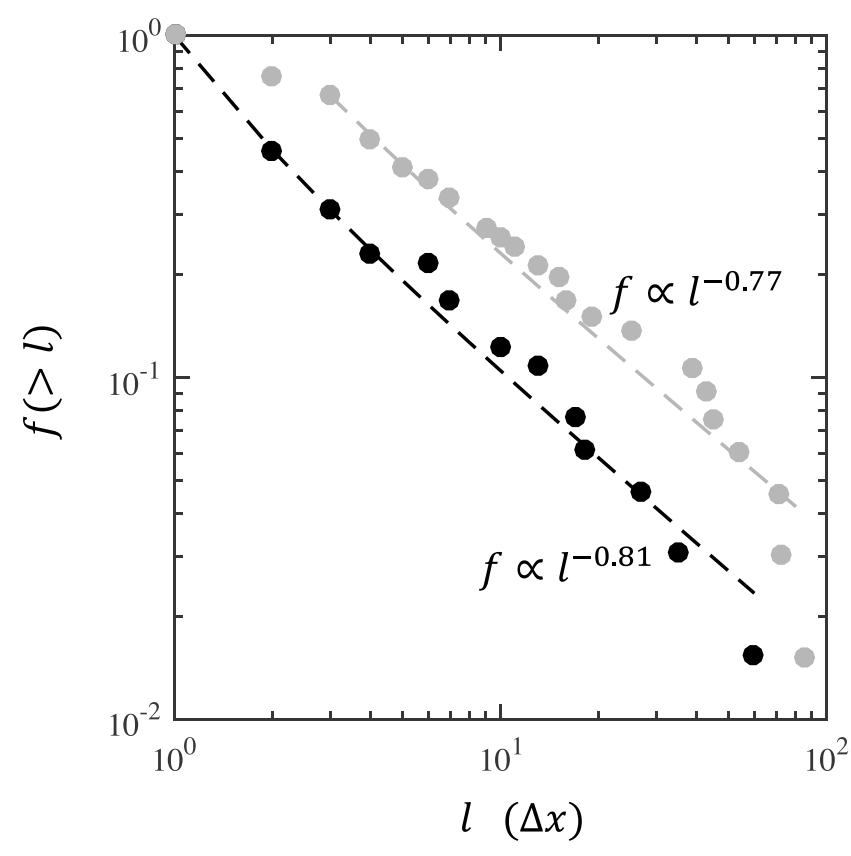

Figure 15. Exceedance probability distributions output from the modeled wet-dry record of the alluvial channel model shown in Figure 14 (gray line). Solid black circles correspond to wet reaches, with exponent of -0.81 . Solid gray circles are the exceedance probability from the corresponding dry series, with an exponent -0.77 . The fraction wet in this example is 0.7 . tional Brownian motion to have a spectral exponent of 1.8. The power spectrum of artificial domains of exceedance scales as $v^{-1.27}$. These results suggest that the heavy-tailed and potentially power law scaling of the wet and dry reach length distribution is directly attributable to the self-affinity present in the bedrock depth and channel elevation data.

\subsection{Scaling of the Stochastic Models}

The alluvial channel model is a discrete stochastic diffusion model. There are many variations of discrete stochastic models, commonly referred to as surface growth models. One significant focus of surface growth models is on determining whether or not a particular model, or class of models, have a corresponding stochastic partial differential equation. For example, the "random deposition with surface relaxation" process (Family, 1986) is known to map on to a linear diffusion equation with additive noise (Barabasi \& Stanley, 1995). A continuum version of the alluvial channel model is not known; however, the model rules bear a functional resemblance to the sandpile model developed by Bak et al. (1987) and the Kardar-Parisi-Zhang (KPZ) equation (Kardar et al., 1986). In the sandpile model, grains are added randomly to a sloping surface, such that the entire interface is driven to an unstable critical point permitting spontaneous avalanches (or fluxes of sediment) with a power law distribution of avalanche sizes. Our model does not permit avalanches. However, with a power law flood distribution driving changes in the profile, the alluvial channel model takes on a qualitatively similar character to the sandpile model. The KPZ equation has been studied in relation to sandpiles, and 
under a variety of conditions it appears to be a continuum analog of sandpiles (Mehta et al., 1996). As will be discussed, these two models can provide insight into the modeling results we have presented.

A wide variety of surface growth models collapse into a subset of groups, or universality classes, which differ only in the behavior of a small set of scaling parameters. A full analysis of the alluvial channel model scaling properties is beyond the scope of this paper, but warrants some preliminary discussion. The interface width, defined as

$$
W(L, t)=\sqrt{\frac{1}{L} \sum_{i=1}^{L}[z(i, t)-\bar{z}(t)]^{2}}
$$

characterizes the temporal evolution of an interface with surface growth. The KPZ equation which has been linked to erosional topography (Pelletier, 2007; Sornette \& Zhang, 1993), has two scaling regimes; in the first regime interface width scales as $W(L, t) \sim t^{b}$ where the growth exponent is $b=1 / 3$, while in the second regime the interface width saturates $(b \rightarrow 0$ as $t \rightarrow \infty)$. Amar and Family (1990) showed the Hausdorf (fractal) dimension of the KPZ equation is $H=0.4$. The spectral scaling exponent $\beta$ and $H$ are related as $\beta=2 H+1$ (Turcotte $\&$ Schubert, 2002), and the KPZ in two dimensions has a wave number spectral scaling exponent of $\beta=1.8$. For a fGn with power spectral exponent $\beta$, level crossing sets (i.e., intersection lengths of a signal about a constant line) have been shown to have power law frequency size distributions where the distribution of segments of length $s$ is $f(>s) \sim s^{-(1-H / 2)}$ (Kondev \& Henley, 1995). In terms of $\beta$, the distribution would be the $f(>s) \sim s^{(\beta-5) / 4}$. A fGn with $\beta=1.8$ corresponds to $f(>s) \sim s^{-0.8}$ (Pelletier \& Turcotte, 1997; Pelletier \& Turcotte, 1999; Pelletier, 1999), which is very near to the empirical values of $m=0.75$ and 0.78 (Figure 3).

In the alluvial channel model, we find the interface width scaling is multiaffine such that there are at least two growth exponents; first $b_{1} \approx 1 / 2$, followed by a second regime where $b_{2} \approx 1 / 3$, then finally followed by crossover to a saturation regime (i.e., $b=0$ ). This multiaffinity arises from the prescribed power law forcing in the stochastic sediment flux (Barabasi \& Stanley, 1995). We hypothesize that the existence of the sequence of $b_{2} \approx 1 / 3$ followed by saturation of widths, and the robust wave number spectral scaling of modeled residual elevation profiles $\left(P(\mathrm{k}) \sim k^{-1.8}\right)$ suggests that the alluvial channel model is in the KPZ universality class.

Power laws are usually associated with a single-scale invariant process or mechanism acting across all scales. However, this is not always the case. For example, shoreface erosion is an apparent continuous power law across a broad range of time scales but with well-known and identifiable processes acting separately across different scales (Lazarus et al., 2011). Similarly, our work shows that the apparently continuous power law frequency size distribution of wet and dry reach lengths are the result of two mechanisms operating over different length scales, where both controls can be associated with similar mechanisms that generate spatial invariance.

\subsection{Ecological Applications}

A mechanistic understanding and accurate characterization of landscape processes that give rise to fractal spatial distributions is necessary to determine whether the dynamics of biological and ecological systems embedded in fractal domains are the result of inherited properties (e.g., a forced response to a fractal landscape) or internal ecological processes that give rise to fractal behavior (e.g., ecological chaos). In arid and semiarid fluvial systems, riparian forests function as ecological keystones (Stromberg et al., 2013) and support high levels of biodiversity (Katz et al., 2012). The spatial distribution of gaps in habitat space and resource availability determines ecological connectivity and therefore many ecosystem metrics, for example, biodiversity (With \& King, 1999). Ecological and hydrological connectivity vary as a function of the fractal dimension (Cushman et al., 2012). The neutral landscape modeling paradigm (Gardner et al., 1987) is one approach to quantify the dependence of ecological processes on structural properties of landscapes. In the San Pedro River, the structural property would be the fractal frequency size distribution of both wet reaches (quantifying habitat size distribution) and dry reaches (quantifying habitat connectivity). While the time evolution of wet and dry reach length is not explicitly resolved in our model, the results suggest a reach of arbitrary length does not dry out simultaneously, but instead can be viewed as a progressive fragmentation process whereby a reach length differentiates into progressively smaller wet reaches. This progressive fragmentation would mean that as a river dries out in time the habitat patches for species dependent on perennial conditions would become progressively smaller as well. Such fragmentation could lead to less resilience of these biological populations (Datry et al., 2017). Since the fractal dimension $m$ is measured with respect to 
the driest month of the year, $m$ quantifies the maximum degree of year to year reach fragmentation due to drying. This provides a useful ground truth for numerical models of dryland riparian ecosystems. While our study approaches the scale-dependent controls of wet and dry reach length through analysis of two separate models, the basic elements of both models could readily be incorporated into a single framework to explore the coupling of ecological processes and multiscale hydrologic and geomorphic variability.

\subsection{Potential Broader Implications}

The results of this paper have potentially important implications for understanding spatiotemporal complexity in aspects of alluvial channels not considered here. For example, the residence time distributions for water have been observed to be fractal, a fact that has been argued to be the results of surface-watergroundwater interactions influenced by channel and or network morphology (e.g., Cardenas, 2008; McGuire et al., 2005). Fractal variations in stream water chemistry have also been observed to be fractal (e.g., Kirchner \& Neal, 2013). The work of this paper extends our knowledge of the fractal properties of these hydrologic aspects of alluvial systems to aspects of the channel bed topography that may, given the tight coupling between geomorphology and hydrology documented here for the San Pedro River, help explain fractal aspects of hydrology that have attracted the interest of many in the hydrologic research community.

\section{Conclusions}

This study considered the multiscale spatial and temporal hydrologic and geomorphic variability San Pedro River in southeastern Arizona. This was motivated by the observed power law frequency size distribution of wet and dry reaches of the San Pedro River. We showed how the observed distribution of wet and dry reaches is consistent with self-affine fractal variations of the DTB and the channel longitudinal profile. At large spatial scales, spatial variations in DTB change the accommodation space for groundwater, driving spatial variations in surface water discharge. At small spatial scales, the longitudinal profile controls spatial variations in surface water discharge by changing the distance between the channel bed and the water table. Topography is typically assumed to control the shape of the water table, except in arid and semiarid environments. The top down model shows that for arid environments where topography does not control the water table profile, a close relationship between topography and the water table still exists resulting in rich fractal behavior reminiscent of results for topographically controlled water tables (Wörman et al., 2007). More broadly, this work highlights how tight coupling possible between hydrologic and geomorphic processes of dryland alluvial rivers can result in complex spatiotemporal behavior.

Acknowledgments

We wish to thank Giovanni Coco, Eli Lazarus, and two anonymous reviewers for comments that substantially improved this manuscript. The wet/dry data set was created by the Nature Conservancy in collaboration with the Bureau of Land Management, and the effort of citizen science volunteers. Most data used in this research are available in the supporting information.

\section{References}

Alstott, J., Bullmore, E., \& Plenz, P. (2014). Powerlaw: A Python package for analysis of heavy-tailed distributions. PLoS ONE, 9(1). https://doi.org/10.1371/journal.pone.0085777

Amar, J. G., \& Family, F. (1990). Numerical solution of a continuum equation for interface growth in $2+1$ dimensions. Physical Review A, 41(6), 3399-3402. https://doi.org/10.1103/PhysRevA.41.3399

Baillie, M. N., Hogan, J. F., Ekwurzel, B., Wahi, A. K., \& Eastoe, C. J. (2007). Quantifying water sources to a semiarid riparian ecosystem, San Pedro River, Arizona. Journal of Geophysical Research, 112, G3S02. https://doi.org/10.1029/2006JG000263

Bak, P., Tang, C., \& Wiesenfeld, K. (1987). Self-organized criticality: An explanation of the $1 / f$ noise. Physical Review Letters, 59(4), 381-384. https://doi.org/10.1103/PhysRevLett.59.381

Barabasi, A. L., \& Stanley, H. E. (1995). Fractal concepts in surface growth. N. Y.: Cambridge Univ. Press. https://doi.org/10.1017/CBO9780511599798 Bauke, H. (2007). Parameter estimation for power-law distributions by maximum likelihood methods. Eur. Phys. J. B., 58(2), 167-173. https://doi.org/10.1140/epjb/e2007-00219-y

Begin, Z. B. (1988). Application of a diffusion erosion model to alluvial channels which degrade due to base level lowering. Earth Surface Processes and Landforms, 13(6), 487-500. https://doi.org/10.1002/esp.3290130603

Bull, W. B. (1997). Discontinuous ephemeral streams. Geomorphology, 19(3-4), 227-276. https://doi.org/10.1016/S0169-555X(97)00016-0

Cardenas, M. B. (2008). Surface water-groundwater interface geomorphology leads to scaling of residence times. Geophysical Research Letters, 35, L08402. https://doi.org/10.1029/2008GL033753

Cho, J. Y. N., Newell, R. E., \& Sachse, G. W. (2000). Anomalous scaling of mesoscale tropospheric humidity fluctuations. Geophysical Research Letters, 27(3), 377-380. https://doi.org/10.1029/1999GL010846

Clauset, A. C., Shalizi, R., \& Newman, M. E. J. (2009). Power-law distributions in empirical data. SIAM Review, 8(1), 89-119. https://doi. org/10.1214/13-AOAS710

Cook, J. P., A. Youberg, P. A. Pearthree, J. A. Onken, B. J. MacFarlane, D. E. Haddad, et al. (2009). Mapping of Holocene river alluvium along the San Pedro River, Aravaipa Creek, and Babocamari River, southeastern Arizona (Digital Map RM-1). Tucson, AZ: Arizona Geological Survey. Online data available at http://repository.azgs.az.gov/uri_gin/azgs/dlio/799

Cordova, J. T., J. E. Dickinson, K. R. Beisner, C. B. Hopkins, J. R. Kennedy, D. R. Pool, et al. (2013). Hydrology of the middle San Pedro Watershed, southeastern Arizona (U.S. Geological Survey Scientific Investigations Report 2013-5040, 77 p.). Reston, VA: U.S. Geological Survey. https://doi.org/10.3133/sir20135040 
Cushman, S. A., Shirk, A., \& Landguth, E. L. (2012). Separating the effects of habitat area, fragmentation and matrix resistance on genetic differentiation in complex landscapes. Landscape Ecology, 27(3), 369-380. https://doi.org/10.1007/s10980-011-9693-0

Datry, T., Corti, R., Heino, J., Hugueny, B., Rolls, R. J., \& Ruhí, A. (2017). Habitat fragmentation and metapopulation, metacommunity, and metaecosystem dynamics in intermittent rivers and ephemeral streams. In Intermittent Rivers and Ephemeral Streams, (pp. 377-403). https://doi.org/10.1016/B978-0-12-803835-2.00014-0

Datry, T., Larned, S. T., \& Tockner, K. (2014). Intermittent rivers: A challenge for freshwater ecology. BioSciences, 64(3), 229-235. https:// doi.org/10.1093/biosci/bit027

Dibiase, R. A., \& Whipple, K. X. (2011). The influence of erosion thresholds and runoff variability on the relationships among topography, climate, and erosion rate. Journal of Geophysical Research, 116, F04036. https://doi.org/10.1029/2011JF002095

Family, F. (1986). Scaling of rough surfaces: effects of surface diffusion. Journal of Physics A, 19(8), L441-L446. https://doi.org/10.1088/ 0305-4470

Fan, N., Singh, A., Guala, M., Foufoula-Georgiou, E., \& Wu, B. (2016). Exploring a semimechanistic episodic Langevin model for bed load transport: Emergence of normal and anomalous advection and diffusion regimes. Water Resources Research, 52, 2789-2801. https://doi. org/10.1002/2015WR018023

Farid, A., Rautenkranz, D., Goodrich, D. C., Marsh, S. E., \& Sorooshian, S. (2006). Riparian vegetation classification from airborne laser scanning data with an emphasis on cottonwood trees. Canadian Journal of Remote Sensing, 32(1), 15-18. https://doi.org/10.5589/m06-003

Fletcher, R. C., \& Hallet, B. (1983). Unstable extension of the lithosphere: A mechanical model for basin-and-range structure. Journal of Geophysical Research, 88(B9), 7457-7466. https://doi.org/10.1029/JB088iB09p07457

Fonstad, M. A., \& Marcus, W. A. (2003). Self-organized criticality in riverbank systems. Annals of the American Association of Geographers, 93(2), 281-296. https://doi.org/10.1111/1467-8306.9302002

Gardner, R. H., Milne, B. T., Turner, M. G., \& O'Neill, R. V. (1987). Neutral models for the analysis of broad-scale landscape pattern Landscape Ecology, 1(1), 19-28. https://doi.org/10.1007/BF02275262

Godsey, S. E., \& Kirchner, J. W. (2014). Dynamic, discontinuous stream networks: Hydrologically driven variations in active drainage density, flowing channels and stream order. Hydrological Processes, 61(8), 1200-1213. https://doi.org/10.1111/fwb.12645

Gutenberg, B., \& Richter, C. F. (1956). Magnitude and energy of earthquakes. Annals of Geophysics, 9, 1-15. https://doi.org/10.4401/ag5590

Haitjema, H. M., \& Mitchell-Bruker, S. (2005). Are water tables a subdued replica of the topography? Ground Water, O(0). https://doi.org/10.1111/j.1745-6584.2005.00090.x

Hereford, R. (1993), Entrenchment and widening of the upper San Pedro River, Arizona, Geological Society of America Special Papers, 282, 46 p.

Hereford, R., \& Betancourt, J. L. (2009). Historic geomorphology of the San Pedro River: Archival and physical evidence. In J. C. Stromberg, \& B. Tellman (Eds.), Ecology and conservation of the San Pedro River, (pp. 232-250). Tucson, Arizona: University of Arizona Press.

Hill, B. M. (1975). A simple general approach to inference about the tail of a distribution. Annals of Statistics, 3(5), 1163-1174. https://doi. org/10.1214/aos/1176343247

Huang, J., \& Turcotte, D. L. (1989). Fractal mapping of digitized images: Applications to the topography of Arizona and comparisons with synthetic images. Journal of Geophysical Research, 94(B6), 7491. https://doi.org/10.1029/JB094iB06p07491

Jaeger, K. L., Sutfin, N. A., Tooth, S., Michaelides, K., \& Singer, M. (2017). Geomorphology and sediment regimes of intermittent rivers and ephemeral streams. In T. Datry, N. Bonada, \& A. Boulton (Eds.), Intermittent rivers and ephemeral streams: Ecology and Management, (pp. 21-49). London: Academic Press. https://doi.org/10.1016/B978-0-13-803835-2.00002-4

Juracek, K. E., \& Fitzpatrick, F. A. (2009). Geomorphic applications of stream-gage information. River Research and Applications, 25, 329-347. https://doi.org/10.1002/rra.1163

Kardar, M., Parisi, G., \& Zhang, Y. C. (1986). Dynamic scaling of growing interfaces. Physical Review Letters, 56(9), 889-892. https://doi.org/ 10.1103/PhysRevLett.56.889

Katz, G. L., Denslow, M. W., \& Stromberg, J. C. (2012). The Goldilocks effect: intermittent streams sustain more plant species than those with perennial or ephemeral flow. Freshwater Biology, 57(3), 467-480. https://doi.org/10.1111/j.1365-2427.2011.02714.x

Kirchner, J. W., \& Neal, C. (2013). Universal fractal scaling in stream chemistry and its implications for solute transport and water quality trend detection. Proceedings of the National Academy of Sciences of the United States of America, 110(30), 12,213-12,218. https://doi.org/ $10.1073 /$ pnas.1304328110

Kondev, J., \& Henley, C. L. (1995). Geometrical exponents of contour loops on random Gaussian surfaces. Physical Review Letters, 74(23), 4580-4583. https://doi.org/10.1103/PhysRevLett.74.4580

Lague, D., Hovius, N., \& Davy, P. (2005). Discharge, discharge variability, and the bedrock channel profile. Journal of Geophysical Research, 110, F04006. https://doi.org/10.1029/2004JF000259

Lazarus, E., Ashton, A., Murray, A. B., Tebbens, S., \& Burroughs, S. (2011). Cumulative versus transient shoreline change: Dependencies on temporal and spatial scale. Journal of Geophysical Research, 116, F02014. https://doi.org/10.1029/2010JF001835

Malamud, B. D., Morein, G., \& Turcotte, D. L. (1998). Forest fires: An example of self-organized critical behavior. Science, 281(5384), 1840-1842. https://doi.org/10.1126/science.281.5384.1840

Malamud, B. D., \& Turcotte, D. L. (2006). The applicability of power-law frequency statistics to floods. Journal of Hydrology, 322(1-4), 168-180. https://doi.org/10.1016/j.jhydrol.2005.02.032

Malamud, B. J., \& Turcotte, D. L. (1999). Self-affine time series: I. Generation and analyses, Adv. Geophys., 40, 1-90. https://doi.org/ 10.1016/S0065-2687(08)60293-9

Malevergne, Y., Pisarenko, V., \& Sornette, D. (2005). Empirical distributions of stock returns: between the stretched exponential and the power law. Quantitative finance, 5(4), 379-401. https://doi.org/10.1080/14697680500151343

McGuire, K. J., McDonnell, J. J., Weiler, M., Kendall, C., McGlynn, B. L., Welker, J. M., \& Seibert, J. (2005). The role of topography on catchment-scale water residence time. Water Resources Research, 41, W05002. https://doi.org/10.1029/2004WR003657

Mehta, A., Luck, J. M., \& Needs, R. J. (1996). Dynamics of sandpiles: Physical mechanisms, coupled stochastic equations, and alternative universality classes. Physical Review E, 53(1), 92-102. https://doi.org/10.1103/PhysRevE.53.92

Murray, A. B., \& Paola, C. (1994). A cellular model of braided rivers. Nature, 371(6492), 54-57. https://doi.org/10.1038/371054a0

Neuman, S. P. (1990). Universal scaling of hydraulic conductivities and dispersivities in geologic media. Water Resources Research, 26(8), 1749-1758. https://doi.org/10.1029/WR026i008p01749

O'Loughlin, E. M. (1981). Saturation regions in catchments and their relation to soil and topographic properties. Journal of Hydrology, 53(3-4), 229-246. https://doi.org/10.1016/0022-1694(81)90003-2 
Onken, J., Cook, J. P., Youberg, A., \& Pearthree, P. A. (2014). Geoarchaeological dating of Holocene stream terraces along the San Pedro River, southeastern Arizona, USA. Quaternary International, 342, 20-32. https://doi.org/10.1016/j.quaint.2013.10.033

Palmer, M. A., Reidy, C., Liermann, C., Nilsson, C., Florke, M., Alcamo, J., et al. (2008). Climate change and world's river basins: anticipating management options. Frontiers in Ecology and the Environment, 6(2), 81-89. https://doi.org/10.1890/060148

Paola, C. (1992). The large-scale dynamics of grain-size variation in alluvial basins, 1: Theory. Basins Research, 4(2), 73-90. https://doi.org/ 10.1111/j.1365-2117.1992.tb00145.x

Pearthree, P. A., and J. P. Cook (2015), Geology and geomorphology of the San Pedro River, southeastern Arizona, Arizona Geological Society Special Paper 10, 23 p., Digital document available online at http://repository.azgs.az.gov/uri_gin/azgs/dlio/1633.

Pelletier, J. D. (1998). The power-spectral density of atmospheric temperature from time scales of 10-2 to 106 yr. Earth and Planetary Science Letters, 91(3-4), 291-301. https://doi.org/10.1016/j.geomorph.2007.04.015

Pelletier, J. D. (1999). Statistical self-similarity of volcanism and magmatism. Journal of Geophysical Research, 104(B7), 15425-15438. https://doi.org/10.1029/1999JB900109

Pelletier, J. D. (2007). Fractal behavior in space and time in a simplified model of fluvial landform evolution. Geomorphology, 91(3-4), 291-301. https://doi.org/10.1016/j.geomorph.2007.04.015

Pelletier, J. D., \& DeLong, S. (2005). Oscillations in arid alluvial channels. Geology, 32(8), 713-716. https://doi.org/10.1130/G20512.1

Pelletier, J. D., Malamud, B. D., Blodgett, T., \& Turcotte, D. L. (1997). Scale-invariance of soil moisture variability and its implications for the frequency-size distribution of landslides. Engineering Geology, 48(3-4), 255-268. https://doi.org/10.1016/S0013-7952(97)00041-0

Pelletier, J. D., \& Turcotte, D. L. (1997). Long-range persistence in climatological and hydrological time series: Analysis, modeling, and application to drought hazard assessment. Journal of Hydrology, 203(1-4), 198-208. https://doi.org/10.1016/S0022-1694(97)00102-9

Pelletier, J. D., \& Turcotte, D. L. (1999). Self-affine time series: II. Applications and models. Advances in Geophysics, 40, 91-166. https://doi. org/10.1016/S0065-2687(08)60294-0

Perron, J. T., Kirchner, J. W., \& Dietrich, W. E. (2008). Spectral evidence of characteristic spatial scales and non-fractal structure in landscapes. Journal of Geophysical Research, 113, F04003. https://doi.org/10.1029/2007JF000866

Pool, D. R., \& Coes, A. L. (1999). Hydrogeologic investigations of the Sierra Vista subwatershed of the upper San Pedro basin, Cochise County, Southeast Arizona (USGS Water-Resources Investigation Report 99-4197, 41 p.). Tucson, AZ: U.S. Geological Survey.

Richard, S. M., T. C. Shipman, L. C. Greene, and R. Harris (2007), Estimated depth to bedrock in Arizona, v.1.0: Arizona Geological Survey Digital Geologic Map DGM-52, 9 p., map scale 1:1,000,000

Rushton, K. (2007). Representation in regional models of saturated river-aquifer interaction for gaining/losing rivers. Journal of Hydrology, 334(1-2), 262-281. https://doi.org/10.1016/j.jhydrol.2006.10.008

Sapozhnikov, V. B., \& Foufoula-Georgiou, E. (1997). Experimental evidence of dynamic scaling and indications of self-organized criticality in braided rivers. Water Resources Research, 33(8), 1983-1991. https://doi.org/10.1029/97WR01233

Singer, M. B., \& Michaelides, K. (2014). How is topographic simplicity maintained in ephemeral dryland channels? Geology, 42(12), 1091-1094. https://doi.org/10.1130/G36267.1

Sornette, D., \& Zhang, Y. C. (1993). Non-linear Langevin model of geomorphic erosion processes. Geophysical Journal International, 113(2), 382-386. https://doi.org/10.1111/j.1365-246X.1993.tb00894.x

Stromberg, J., McCluney, K. E., Dixon, M. D., \& Meixner, T. (2013). Dryland riparian ecosystems in the American Southwest: Sensitivity and resilience to climatic extremes. Ecosystems, 16(3), 411-415. https://doi.org/10.1007/s10021-012-9606-3

Tóth, J. (1963). A theoretical analysis of groundwater flow in small drainage basins. Journal of Geophysical Research, 68(16), 4795-4812. https://doi.org/10.1029/JZ068i016p04795

Tucker, G. E. (2004). Drainage basin sensitivity to tectonic and climatic forcing: Implications of a stochastic model for the role of entrainment and erosion thresholds. Earth Surface Processes and Landforms, 29(2), 185-205. https://doi.org/10.1002/esp.1020

Tucker, G. E., \& Bras, R. L. (2000). A stochastic approach to modeling the role of rainfall variability in drainage basin evolution. Water Resources Research, 36(7), 1953-1964. https://doi.org/10.1029/2000WR900065

Turcotte, D. L., \& Greene, L. (1993). A scale-invariant approach to flood-frequency analysis. Stochastic Hydrology and Hydraulics, 7(1), $33-40$.

Turcotte, D. L., \& Schubert, G. (2002). Geodynamics, (Second ed.p. 456). New York: Cambridge University Press. https://doi.org/10.1017/ CBO9780511807442

Turner, D. S., \& Richter, H. E. (2011). Wet/dry mapping: using citizen scientists to monitor the extent of perennial surface flow in dryland regions. Environmental Management, 47(3), 497-505. https://doi.org/10.1007/s00267-010-9607-y

U.S. Geological Survey, 2016, National Water Information System data available on the World Wide Web (USGS Water Data for the Nation), (accessed November 22, 2016), at URL (http://waterdata.usgs.gov/nwis/).

U.S. Geological Survey, 2018, National Water Information System data available on the World Wide Web (USGS Water Data for the Nation), accessed (accessed January 10, 2018), at URL (http://waterdata.usgs.gov/nwis/).

Venugopal, V., Foufoula-Georgiou, E., \& Sapozhnikov, V. (1999). Evidence of dynamic scaling in space-time rainfall. Journal of Geophysical Research, 110, 599-610, https://doi.org/10.1029/2004JD005395

Waters, M. R., \& Haynes, C. V. (2001). Late Quaternary arroyo formation and climate change in the American Southwest. Geology, 29(5), 399-402. https://doi.org/10.1130/0091-7613(2001)029<0399:LQAFAC >2.0.CO;2

Werner, B. T. (1995). Eolian dunes: Computer simulation and attractor interpretation. Geology, 23(12), 1107-1110. https://doi.org/10.1130/ 0091-7613(1995)023<1107:EDCSAA>2.3.CO;2

Werner, B. T. (1999). Complexity in natural landform patterns. Science, 284(5411), 102-104. https://doi.org/10.1126/science.284.5411.102

White, E. P., Enquist, B. J., \& Green, J. L. (2008). On estimating the exponent of power-law frequency distributions. Ecology, 89(4), 905-912. https://doi.org/10.1890/07-1288.1

With, K. A., \& King, A. W. (1999). Dispersal success on fractal landscapes: A consequence of lacunarity thresholds. Landscape Ecology, 14(1), 73-82. https://doi.org/10.1023/A:1008030215600

Woessner, W. W. (2000). Stream and fluvial plain groundwater interactions: rescaling hydrogeologic thought. Ground Water, 38(3), 423-429. https://doi.org/10.1111/j.1745-6584.2000.tb00228.x

Wörman, A., Packman, A. I., Marklund, L., Harvey, J. W., \& Stone, S. H. (2007). Fractal topography and subsurface water flows from fluvial bedforms to the continental shield. Geophysical Research Letters, 34, L07402. https://doi.org/10.1029/2007GL029426 